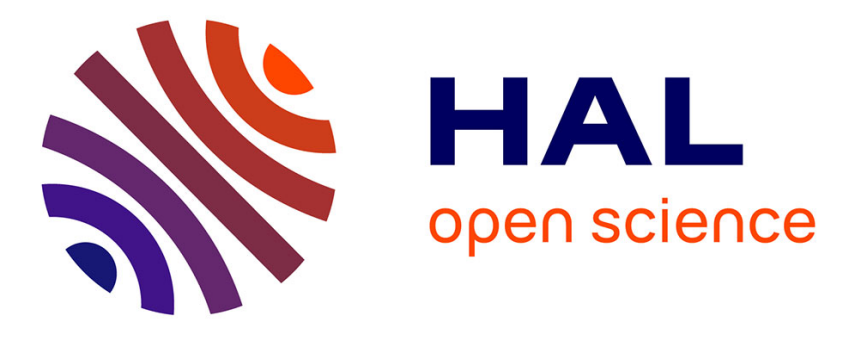

\title{
HNF4g invalidation prevents diet-induced obesity via intestinal lipid malabsorption
}

\author{
Marine Halbron, Olivier Bourron, Fabrizio Andreelli, Cecile Ciangura, Sophie \\ Jacqueminet, Marc Popelier, Frederic Bosquet, Stephanie Rouanet, Chloe \\ Amouyal, Agnes Hartemann
}

\section{To cite this version:}

Marine Halbron, Olivier Bourron, Fabrizio Andreelli, Cecile Ciangura, Sophie Jacqueminet, et al.. HNF4g invalidation prevents diet-induced obesity via intestinal lipid malabsorption. Journal of Endocrinology, 2021, 21 (7), pp.409-412. 10.1530/JOE-21-0092 . hal-03388414

\section{HAL Id: hal-03388414 https://hal.sorbonne-universite.fr/hal-03388414}

Submitted on 20 Oct 2021

HAL is a multi-disciplinary open access archive for the deposit and dissemination of scientific research documents, whether they are published or not. The documents may come from teaching and research institutions in France or abroad, or from public or private research centers.
L'archive ouverte pluridisciplinaire HAL, est destinée au dépôt et à la diffusion de documents scientifiques de niveau recherche, publiés ou non, émanant des établissements d'enseignement et de recherche français ou étrangers, des laboratoires publics ou privés. 

Soula $^{1}$, Armelle Leturque ${ }^{1}$, Fabrizio Andreelli ${ }^{1,3,4}$, Karine Clément ${ }^{1,3}$, Patricia Serradas ${ }^{1}$, Agnès Ribeiro $^{1 *}$

1- Sorbonne Université, INSERM, Nutrition and obesities: systemic approaches, F-75013

8 Paris, France

9 2- AP-HP Hôpital Pitié-Salpêtrière-Charles Foix, Functional Coprology Department, F-75013

10 Paris, France

11 3- AP-HP Hôpital Pitié-Salpêtrière-Charles Foix, Nutrition Department, F-75013 Paris,

12 France

4- AP-HP Hôpital Pitié-Salpêtrière-Charles Foix, Diabetology-Metabolism Department, F75013 Paris, France

15

16

Present address:

E G-I: Department of Psychiatry - Division of Molecular Therapeutics, Columbia University Irving Medical Center, New York, NY, USA

*Corresponding author: Agnès Ribeiro, Sorbonne Université, INSERM, Nutrition and obesities: systemic approaches, F-75013 Paris, France - e-mail: agnes.ribeiro@sorbonne$\underline{\text { universite.fr }}$

Short title: HNF4G and lipid malabsorption in intestine

Word count: $4409-4895$ words

Keywords: HNF-4gamma, intestine, obesity, lipid malabsorption, GLP-1, high-fat/high fructose diet. 


\section{Abstract}

Changes in dietary habits have occurred concomitantly with a rise of type 2 diabetes (T2D) and obesity. Intestine is the first organ facing nutrient ingestion and has to adapt its metabolism with these dietary changes. HNF-4 $\gamma$, a transcription factor member of the nuclear receptor superfamily and mainly expressed in intestine has been suggested involved in susceptibility to T2D. Our aim was to investigate the role of HNF-4 $\gamma$ in metabolic disorders and related mechanisms. Hnf4g $\mathrm{g}^{-/-}$mice were fed high-fat/high-fructose (HF-HF) diet for 6 weeks to induce obesity and T2D. Glucose homeostasis, energy homeostasis in metabolic cages, body composition and stool energy composition, as well as gene expression analysis in jejunum were analyzed. Despite an absence of decrease in calorie intake, of increase in locomotor activity or energy expenditure, $\mathrm{Hnf}_{4 \mathrm{~g}} \mathrm{~g}^{-/}$mice fed HF-HF are protected against weight gain after 6 weeks of HF-HF diet. We showed that $\mathrm{Hnf}_{4 \mathrm{~g}^{-/}}$mice fed HF-HF display an increase in fecal calorie loss, mainly due to intestinal lipid malabsorption. Gene expression of lipid transporters, Fatp4 and Scarb1 and of triglyceride-rich lipoprotein secretion proteins, Mttp and ApoB are decreased in gut epithelium of $\mathrm{Hnf}_{4} \mathrm{~g}^{-/}$mice fed HF-HF, showing the HNF-4 $\gamma$ role in intestine lipid absorption. Furthermore, plasma GLP-1 and jejunal GLP-1 content are increased in Hnf4 $\mathrm{g}^{-/-}$ mice fed HF-HF, which could contribute to the glucose intolerance protection. The loss of HNF$4 \gamma$ leads to a protection against a diet-induced weight gain and to a deregulated glucose homeostasis, associated with lipid malabsorption. 


\section{Introduction}

HNF-4 belongs to the nuclear receptor superfamily and in mammals, two paralog genes encode the HNF-4 $\alpha$ and HNF-4 $\gamma$ forms. HNF-4 $\alpha$ is expressed in liver, kidney, pancreas and intestine (Benoit et al., 2006). Numerous studies in vivo and in vitro have shown that HNF-4 $\alpha$ plays pleiotropic roles in liver functions and is a central transcription factor at the crossroads between epithelial morphogenesis and functions (Battle et al., 2006; Hwang-Verslues and Sladek, 2010; Ribeiro et al., 2007). Intestinal mice $H n f 4 a$ gene invalidation induces impairment of intestinal epithelium homeostasis, regeneration, cell architecture and fatty acid uptake (Cattin et al., 2009; Frochot et al., 2012; Montenegro-Miranda et al., 2020; Saandi et al., 2013).

HNF- $4 \gamma$ is expressed mainly in intestine and colon, in kidney and to a lesser extent in pancreas (Bookout et al., 2006), being almost absent from liver (Plengvidhya et al., 1999; Taraviras et al., 2000). HNF-4 $\gamma$ is highly expressed during intestine specification (Li et al., 2009). Recently, a novel variant of $\mathrm{HNF}-4 \gamma$, designated $\mathrm{HNF}-4 \gamma 2$ was found to promote transactivation capacity and hepatic function of dedifferentiated hepatoma cells better than HNF-4 $\alpha$ (Sasaki et al., 2018). Furthermore, an integrative multi-omics analysis in intestinal organoids highlighted HNF-4 $\gamma$ as a major driver of enterocyte differentiation (Lindeboom et al., 2018). It is noteworthy that the physiological role of HNF- $4 \gamma$ was much less studied than that of HNF- $4 \alpha$ and there is a lack of information on HNF-4 $\gamma$. Using constitutive $H n f 4 g$ gene invalidation model fed control diet, we demonstrated that loss of HNF-4 $\gamma$ leads to an overproduction of GLP-1, leading to an exaggerated glucose-induced insulin secretion that improves glucose tolerance of $\mathrm{Hnf}_{4} \mathrm{~g}^{-/}$mice through an increase in GLP-1 incretin effect and a trophic impact on pancreatic

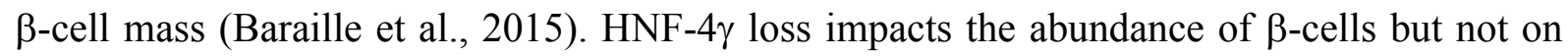
their insulin secretory capacity and led to a resistance to streptozotocin, a $\beta$-cell cytotoxic drug (Baraille et al., 2015). The role of HNF-4 $\gamma$ deserves thus further attention in the susceptibility to type 2 diabetes (T2D) using appropriate mouse model. 
T2D is one of numerous co-morbidities associated with obesity as well as cardiovascular diseases (Stahel et al., 2020). The duration and the amplitude of the post-prandial peak of circulating triglyceride rich lipoproteins (TRL) from intestinal origin are risk of cardiovascular diseases (Bansal et al., 2007; Duez et al., 2008; Hsieh et al., 2008; Nordestgaard et al., 2007). Furthermore, changes of intestinal TRL secretion have been reported in the context of insulin resistance or diabetes, in animal models (Haidari et al., 2002; Vine et al., 2007) and in humans (Duez et al., 2006). There is evidence for an increased basal rate of intestine-specific apolipoprotein (apo)B-48-containing lipoprotein secretion in insulin resistance and T2D (Adeli and Lewis, 2008). Inversely, insulin reduces TRL and apoB-48 secretion (Levy et al., 1996). In insulin resistant fructose-fed hamsters, de novo lipogenesis is enhanced (Haidari et al., 2002; Lewis et al., 2005). Hyperinsulinemic insulin-resistant human subjects display increased production rates of intestinal apoB48-containing lipoproteins (Duez et al., 2006), and in individuals with type 2 diabetes, intestinal chylomicron production is resistant to insulin's acute suppressive effects (Nogueira et al., 2012). The relationships between T2D and lipid metabolism in the context of $h n f 4 g$ invalidation deserve further investigation.

Changes in dietary habits, including increments in calorie and saturated fatty acid intakes, have occurred concomitantly with a rise of T2D and obesity (Shikany and White, 2000). Intestine has to adapt its metabolism to accommodate the increased lipid intake.

The intestine ensures the transport of alimentary fat, which is the most calorie-dense nutrient. Enterocytes ensure the transfer of dietary lipids to the organism through complex processes (Williams, 2008). Triglycerides (TG) are hydrolyzed mainly by pancreatic enzymes into fatty acids and monoglycerides. The uptake of fatty acids occurs by passive diffusion and by a saturable/ protein-mediated mechanism comprising the fatty acid translocase (CD36), the fatty acid-binding protein from the plasma membrane (FABPpm), as well as the fatty acid transport protein (FATP) family (Gimeno et al., 2003; Nordestgaard et al., 2007; Stahl et al., 1999). After 
resynthesis within the endoplasmic reticulum membrane, TG are used to form chylomicrons, the intestine-specific postprandial form of TRL, which will be secreted into the lymph and then directed toward circulation. The assembly of one TRL results from the fusion between one apoB molecule, which is necessary for their formation, and one independently formed TG droplet (Davidson and Shelness, 2000). The microsomal TG transfer protein (MTP) has a prominent role in chylomicron assembly, ensuring the lipidation-dependent stabilization of apoB and the transfer of lipids to the TG droplet in the endoplasmic reticulum lumen (Iqbal and Hussain, 2009). During the postprandial period, TG are also transiently stored in enterocytes, as cytosolic lipid droplets surrounded by proteins such as ADRP, which can be subsequently hydrolyzed to reenter the secretory pathway (Robertson et al., 2003). Thus perturbations of their basal level of expression and/or their nutrient-dependent modulation should interfere with the enterocyte function of dietary lipid absorption and would reveal functional role of HNF-4 $\gamma$ in intestinal absorption of lipids.

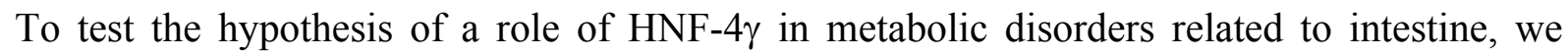
submitted the constitutive $H n f 4 g$ gene invalidation model to a high-fat/high-fructose (HF-HF) diet for 6 weeks, in order to induce obesity and T2D.

\section{Materials and methods}

\section{Animals and treatments}

Total and constitutive $H n f 4 g$ gene invalidation was as previously described (Baraille et al., 2015; Gerdin et al., 2006). Heterozygote $H n f 4 g$ knockout mice $\left(H n f 4 g^{+/-}\right)$were obtained from Deltagen (San Carlos CA, USA). Briefly, Hnf4g knockout mice were generated by homologous recombination using ES cells derived from 129/OlaHsd mouse substrain. F1 mice were generated by breeding chimeras carrying a disrupted $H n f 4 g$ gene with C57BL/6 females resulting in F1 heterozygote offspring. $\mathrm{Hnf}_{4} \mathrm{~g}^{+/-}$mice on a C57BL/6J genetic background, were 
mated to obtain ${ }^{H n f t g-/}$ mice on the same genetic background. $H n f 4 g^{-/}$male mice were compared with $\mathrm{C} 57 \mathrm{Bl} / 6 \mathrm{~J}$ wild-type male WT mice, matched in age and housed in the same room.

Mice were housed in groups and maintained on a 12-hour light-dark cycle with ad libitum access to water and diet: chow diet (CD: 5\% Kcal fat - reference A03/R03, Safe-Diets) or high fat diet (60\% Kcal fat - D12492, Research Diets) with 30\% fructose (Sigma) in drinking water (HF-HF). Diets detail composition are described in Table 1. Mice were 2 month-old when HFHF diet started for 6 weeks. Mice were euthanized by cervical dislocation. Experimental procedures agreed with the French ethical guidelines for animal studies and were approved by the Regional Animal Care and Use Ethic Committee Charles Darwin C2EA - 05, agreement number (\#4132 - $2016021710083817 \mathrm{v} 3)$.

\section{Glucose tolerance test}

Glucose tolerance tests were performed after 6 weeks of HF-HF or control diets. After overnight fasting, mice received a $3.6 \mathrm{~g} / \mathrm{kg}$ glucose load for oral glucose tolerance tests (OGTT). Blood glucose concentrations were measured with a glucometer (Accu-checkGo, Roche). Blood samples ( $70 \mu \mathrm{l}$ at t0 and $10 \mathrm{~min}$ after glucose challenge) were collected from the tail into EDTA pre-coated microvette (Sarstedt). Plasma insulin (Alpco) and total glucagon-like peptide-1 (GLP-1) (Millipore) were measured by ELISA.

\section{Plasma triglyceride levels after an olive oil bolus}

The plasma triglyceride levels after an olive oil bolus were measured after 6 weeks of HF-HF or control diets. After overnight fasting, mice received a 200 microL olive oil load. Blood samples were collected as described in paragraph 2.2 at $0,30,60,90$ and 120 min after the olive oil challenge. Plasma triglyceride concentrations were measured with the kit Triglycerides FS (DiaSys).

Metabolic parameters, body composition and stool analysis 
148 After 4 weeks of HF-HF or control diets, mice were housed individually in metabolic cages

149 (Phenomaster, TSE Systems) 1 week for habituation and 1 week for measurement and were fed

150 ad libitum with control or HF-HF diet. Food and water intake as well as $\mathrm{O} 2$ consumption, $\mathrm{CO} 2$

151 production, respiratory quotient, whole energy expenditure were automated measured. The

152 tridimensional locomotor activity is measured by the spontaneous (voluntary) activity on the

153 cage surface (XY axes) and in height ( $\mathrm{XZ}$ axes). A count is register every time an infrared beam

154 is broken in the horizontal plane or in the vertical plane. The locomotor activity was recorded

155 for 5 consecutive days during nights and days and the mean of records was calculated. The

156 tridimensional locomotor activity is expressed as the sum of the XY activity mean (day and

157 night) and of the XZ activity mean (day and night) as counts in $24 \mathrm{~h} /$ mouse. The whole body

158 composition was analyzed with the Bruker's minispec Whole Body Composition Analyzer. This

159 analyzer for measurement of lean tissue, fat and fluid in living mice is based on Time Domain

160 (TD)-Nuclear magnetic resonance (NMR). Stools were daily collected and stored at $-20^{\circ} \mathrm{C}$.

161 After homogenization, total and, lipid and nitrogen energy contents were as-determined as

162 previously described in (Layec et al., 2013).

163 Intestinal GLP-1 protein content

164 Proximal jejunum, distal ileum, and whole colon were sliced into small pieces, homogenized 165 in ethanol/acid (100\% ethanol/sterile water/ $12 \mathrm{~N} \mathrm{HCl} 74: 25: 1 \mathrm{v} / \mathrm{v} / \mathrm{v})$ solution $(5 \mathrm{ml} / \mathrm{g}$ tissue $)$ and

166 incubated overnight at $4^{\circ} \mathrm{C}$. Homogenates were centrifuged and supernatants were collected for

167 total GLP-1 content measurement using ELISA kit (Millipore).

168 Intestinal epithelial cell isolation and protein concentration measurement

169 After flushing with PBS, jejunum was cut into small pieces and incubated $4 \mathrm{~h}\left(4^{\circ} \mathrm{C}\right)$ in Cell 170 recovery solution (BD Biosciences) containing 2\% protease inhibitors (Sigma). Epithelial cells 171 were filtered, centrifuged, and washed with PBS, to obtain epithelial cell suspension (Archer et 172 al., 2005). Proteins were extracted from an aliquot of epithelial cells with a lysis buffer (Tris 
$173 \mathrm{HCl} 20 \mathrm{mM} \mathrm{pH}$ 7.4, $\mathrm{NaCl} 150 \mathrm{mM}$, EDTA $5 \mathrm{mM}$, Triton 1\%, DOC $0.5 \%$, protease and

174 phosphatase inhibitors). Protein concentration was determined with the BCA protein assay kit 175 (Pierce).

\section{Triglyceride levels in epithelial cells}

177 Lipids were extracted from an aliquot of epithelial cells with five volumes of chloroform178 methanol $(2: 1 \mathrm{vol} / \mathrm{vol})$, with vigorous shaking for $5 \mathrm{~min}$. After centrifugation for $20 \mathrm{~min}$ at $1791,000 \mathrm{~g}$, the lower organic phase was collected and dried at $45^{\circ} \mathrm{C}$ overnight. The triglyceride 180 levels were measured with the TG PAP 150 kit (Biomérieux).

RNA extraction and gene expression analysis

Total RNA were isolated from jejunum epithelial cells with Trizol reagent (MRC). Reverse transcription (RT) was performed with $5 \mu \mathrm{g}$ of RNA. Semi quantitative real-time PCR was

184 performed with SYBR green (Applied) in a Stratagene system. Primer sequences are reported 185 in Table 2.

\section{Statistical Tests}

187 Results are expressed as means \pm SEM. Statistical analyses were performed using GraphPad 188 Prism (GraphPad Software, La Jolla, CA). Identified outliers with the method « ROUT Q=1\% »

189 (Graphpad prism software) were removed. The significance was evaluated by 1-way ANOVA 190 or 2-way ANOVA and followed by four Tukey's multiple comparisons tests: WT vs $\mathrm{Hnf}_{4 g^{-/}}$ on CD, WT vs $H n f 4 g^{-/}$on HF-HF, WT CD vs WT HF-HF, $H n f 4 g^{-/} \mathrm{CD}$ vs $H n f 4 g^{-/}$HFHF. A $P$

192 value $<0.05$ was considered statistically significant.

\section{Results}


198 Metabolic characteristics of $\mathrm{Hnf}_{4} \mathrm{~g}^{-/}$mice were compared with those of WT mice, both groups being fed ad libitum either with control diet or high-fat/high fructose (HF-HF) diet. The body weight gain curves were comparable between WT and $\mathrm{Hnf}_{4} \mathrm{~g}^{-/}$mice fed control diet. There was no weight gain after 6 weeks (99\% for WT vs 94\% for $H n f 4 g^{-/}$) (Fig. 1A). As expected, 6 weeks of HF-HF diet promoted weight gain by $35 \%$ in WT mice but surprisingly, by only $10 \%$ in $H n f 4 g^{-/}$mice (Fig. 1A). We then performed a body composition analysis by NMR. On control diet, $H n f 4 g^{-/}$mice showed a non-significant 1.5-fold higher fat mass than WT mice (Fig. 1B). As expected, on HF-HF diet WT mice showed a 2.4-fold increase in fat mass whereas $H n f 4 g^{-/-}$ mice only 1.5-fold (Fig. 1B). However, on HF-HF diet, the increase in fat mass was 1.6-fold lower in $\mathrm{Hnf}_{4 \mathrm{~g}^{-/}}$mice than in WT mice (Fig. 1B). In parallel, lean mass of $H n f 4 \mathrm{~g}^{-/}$mice was similar to that of WT mice regardless the diet (data not shown). Thus Hnf4g gene invalidation led to a partial protection against diet-induced weight gain characterized by less fat-mass gain. In order to explain such a resistance to weight gain, we analyzed food intake, locomotor activity and energy expenditure.

\section{Impact of high-fat/high-fructose diet on $\mathrm{HnfHg}^{-/-}$mouse energy homeostasis}

We next analyzed the energy homeostasis of WT and $\mathrm{Hnflg}^{-/-}$mice fed control or HF-HF diets in metabolic cages after 5 weeks of diet. We showed that total calorie intake (high-fat pellets and fructose in the drinking water) normalized by mouse body weight was not affected by Hnf4g gene invalidation regardless the diet (Fig. 1C). The XY and XZ axis locomotor activity was next recorded. There was no significant difference between WT and $H n f 4 g^{-/-}$mice for their XYZ axis locomotor activity regardless the diet but HF-HF diet induced a 1.4-fold decrease in the locomotor activity regardless the mouse genotype (Fig. 1D). The calculated energy expenditure (normalized to mouse body weight) of $\mathrm{Hnf}_{4} \mathrm{~g}^{-/-}$mice was similar to that of WT 
mice fed control diet (Fig. 1E). As expected, the energy expenditure of WT fed HF-HF diet is 10\% decreased compared to WT mice fed control diet (Fig. 1E). However, the energy expenditure of $\mathrm{Hnf}_{4} \mathrm{~g}^{-/}$mice fed control diet is similar to that of fed HF-HF diet (Fig. 1E).

Thus, the WT mice weight gain, induced by HF-HF diet, is explained by an increase in fat mass, a decrease in locomotor activity and in energy expenditure. However, the partial protection to diet-induced weight gain of $\mathrm{Hnf}_{4} \mathrm{~g}^{-/-}$mice was not due to a decrease in calorie intake, an increase in locomotor activity nor an energy expenditure. Then, we made the hypothesis that $H n f 4 g$ gene invalidation leads to nutrient malabsorption revealed by HF-HF diet.

\section{Impact of $H n f-4 \gamma$ gene invalidation on nutrient absorption}

234 For assessment of intestinal absorption total calories were measured in feces. We showed a 25\% increase in fecal calorie loss in $H n f 4 g^{-/}$mice fed HF-HF diet compared to WT mice (Fig. 2A). More strikingly, this calorie loss is mainly due to a 4-fold increase of lipids in feces (Fig. 2B) whereas the protein and carbohydrate amounts were similar regardless genotypes and diets (data not shown). The higher calorie loss in $\mathrm{Hnf}_{4} \mathrm{~g}^{-/-}$mice could be responsible of for the protection against weight gain induced by HF-HF diet. We made the hypothesis that the $H n f 4 g$ gene invalidation leads to a lipid malabsorption.

241 We measured the triglyceride level in jejunal epithelial cells and showed that in $\mathrm{Hnf}_{4} \mathrm{~g}^{-/}$mice 242 fed control diet, intra-epithelial triglyceride amount is increased 2-fold (not significant) 243 compared to WT mice. More strikingly, in WT mice fed HF-HF, the intra-epithelial 244 triglycerides are increased 10-fold compared to that of control diet, whereas in $\mathrm{Hnf}_{4} \mathrm{~g}^{-/}$mice, 245 the 2.6-fold increase is not-significant (Fig. 2C).

246 We then analyzed the kinetic of plasma triglyceride concentrations after an olive oil bolus, as 247 reflect of enterocyte triglyceride secretion. The plasma triglyceride concentrations after an olive 
oil bolus are similar in WT and $H n f 4 g^{-/}$mice fed control diet. As expected under HF-HF, the concentration of plasma triglycerides in WT mice is increased 3- fold at 90min compared to that of mice on control diet whereas the concentration of plasma triglycerides in $\mathrm{Hnf}_{4} \mathrm{~g}^{-/}$mice remains similar to that of on control diet (Fig. 2D).

The partial protection to diet-induced weight gain of $\mathrm{Hnf}_{4} \mathrm{~g}^{-/-}$mice could be due to an intestinal lipid malabsorption at uptake step (showed by increased lipids in feces and decreased in jejunal epithelial cells) and at secretion step (showed by plasma concentrations).

Impact of high-fat/high-fructose diet on gene expression involved in lipid absorption in

$H n f 4 g^{-/}$mice gut epithelium

We next analyzed gene expression of lipid membrane transporters in jejunum from $\mathrm{HnfHg}^{-/-}$and WT mice fed control or HF-HF diet (Fig. 3A). The HF-HF diet increased the fatty acid transporter gene expression Fabpm and Cd36, regardless the mouse genotype, $\mathrm{HnfHg}^{-/-}$or WT (Fig. 3A, upper panels). The gene expression of the fatty acid transporter Fatp4 was reduced by 1.8 -fold in $\mathrm{Hnf}_{4 \mathrm{~g}^{-/-}}$mice compared to WT mice, fed control diet and by 1.3 -fold on mice fed HF-HF diet (Fig. 3A, lower left panel). The gene expression of the cholesterol transporter Scarbl (encoding SR-B1) was reduced in $\mathrm{Hnf}_{4} \mathrm{~g}^{-/}$mice compared to WT mice, regardless the diet, CD or HF-HF. However the HF-HF diet increased the Scarb1 gene expression whatever the mouse genotype, $\mathrm{Hnf4g}^{-/-}$or WT (Fig. 3A, lower right panel).

268 Then, we analyzed expression of genes involved in lipid storage (Plin2, encoding Perilipin 2 or 269 ADRP) and secretion (Mttp and $A p o B)$ (Fig. 3B). The HF-HF diet induced an increased gene expression of Plin2 (2.4-fold) and of Mttp (1.8-fold) in WT mice but not in $\mathrm{HnfHg}^{-/-}$mice.

271 However, the expression of Plin2, Mttp and $a p o B$ is lowered in $\mathrm{Hnf}_{4 \mathrm{~g}^{-/}}$mice fed HF-HF diet by 1.5-, 3.9- and 1.8-fold, respectively compared to WT mice fed HF-HF diet (Fig. 3B). 
This decrease in gene expression of lipid transporters, lipid storage and secretion proteins could explain in part the lipids fecal calorie loss suggesting a lipid malabsorption due to lipid transfer failing toward blood circulation.

Note that gene expression of Hnf4a was 1.6- and 2.4-fold increase in $\mathrm{HnfHg}^{-/-}$mice than in WT mice on control and HF-HF diets, respectively (Fig. 3C).

\section{Impact of high-fat/high-fructose diet on $\mathrm{Hnf} 4 \mathrm{~g}^{-/-}$mice glucose homeostasis}

The lipid malabsorption that could protect $H n f 4 g^{-/-}$mice against weight gain induced by an HFHF diet, could also allow a preferential use of glucose and thus protects from a deregulation of glucose homeostasis. We challenged glucose tolerance by an OGTT and as expected, WT mice fed HF-HF present a glucose intolerance compared to WT mice fed control diet (Fig. 4A). The area under the curve (AUC) was 1.8- fold higher in WT mice fed HF-HF diet than in WT mice fed control diet (Fig. 4B). We also confirmed as previously described in Baraille \& al, that $H n f 4 g$ gene invalidation led to improvement of glucose tolerance in mice fed control diet (Fig. 4A) (Baraille et al., 2015). Indeed, the AUC was 1.4- fold lower in $H n f 4 g^{-/-}$mice fed control diet than in WT mice (Fig. 4B). This feature was further exacerbated in $\mathrm{Hnflg}^{-/-}$mice fed HFHF diet compared to WT mice (Fig. 4A) since AUC was 1.8 -fold lower in $\mathrm{Hnf}_{4} \mathrm{~g}^{-/-} \mathrm{HF}-\mathrm{HF}$ fed mice than in WT mice (Fig. 4A). Importantly, AUC of oral glucose tolerance test of $H n f 4 g^{-/-}$ HF-HF fed mice was similar to that of WT control diet fed mice (Fig. 4B). As expected, fasting blood glucose and insulin were increased 1.18- and 2.74- fold respectively, in WT mice fed HFHF compared to control diet (Fig. 4C, D) whereas fasting blood glucose and insulin remained unaffected in $\mathrm{Hnf}_{4 \mathrm{~g}^{-/}}$mice fed HF-HF compared to control diet (Fig. 4C and D). Furthermore, the HF-HF diet induced a 3.3-fold increase of HOMA-IR in WT mice without significant effect 
on HOMA-IR in $H n f 4 g^{-/-}$mice (Fig. 4E). These results indicate that $H n f 4 g$ gene invalidation protects mice against glucose intolerance induced by the HF-HF diet.

\section{Impact of high-fat/high-fructose diet on $\mathrm{Hnf}_{4} \mathrm{~g}^{-/-}$mice GLP-1 intestinal homeostasis}

We then measured the total plasma GLP-1 concentration 10 min after a glucose challenge. As previously described in Baraille \& al, we confirmed that plasma total GLP-1 concentration was 3.3-fold increase in $\mathrm{Hnf}_{4} \mathrm{~g}^{-/}$than in WT mice fed control diet, (Fig. 5A) (Baraille et al., 2015). Although the HF-HF diet induced a 3-fold increase in plasma total GLP-1 concentration in WT mice and a 1.4-fold non-significant increase in $\mathrm{HnfHg}^{-/-}$mice, the plasma total GLP-1 concentration in $\mathrm{Hnf}_{4 \mathrm{~g}^{-/}}$mice fed HF-HF remained 1.53 fold higher than in WT mice fed HFHF (Fig. 5A). We next measured GLP-1 content in mouse jejunum and we showed that GLP-1 content in jejunum of $\mathrm{Hnf}_{4} \mathrm{~g}^{-/}$mice is 2- and 1.7-fold increase in control and HF-HF diet, respectively (Fig. 5B). In jejunum, the level of Gcg mRNA, encoding proglucagon, is increased by HF-HF diet 1.95- and 1.6-fold in WT and $\mathrm{Hnf4g}^{-/-}$mice, respectively (Fig. 5C). These results showed that the Hnf4g gene invalidation leads to an increase in GLP-1 jejunum content that could explain the increase in plasma GLP-1 in response to glucose challenge in mice fed control and HF-HF diet.

\section{Discussion}

Our results demonstrate that the gene invalidation of the nuclear receptor HNF-4 $\gamma$ induces a protection against the weight gain induced by a high-fat/high-fructose diet. The weight gain protection is mainly due to intestinal lipid malabsorption leading to a calorie loss in feces. $\mathrm{Hnf}_{4} \mathrm{~g}^{-/-}$mice were also protected against glucose intolerance induced by the HF-HF diet. An 
increase in jejunal GLP-1 content could participate to this protection via a possible incretin effect.

324 Mice invalidated for $\mathrm{Hnf4g}$ gene were reported to present a lower food intake, associated with lower night energy expenditure, than wild type mice (Gerdin et al., 2006). Our previous results did not show difference in food intake in $H n f 4 \mathrm{~g}^{-/-}$and $W T$ mice fed control diet but a strong improvement of glucose tolerance of $\mathrm{Hnf}_{4} \mathrm{~g}^{-/-}$mice (Baraille et al., 2015), suggesting that HNF$4 \gamma$ could be involved in susceptibility to type 2 diabetes. In order to generate rapid glucose intolerance and insulin resistance, we challenged mice with a high fat and high fructose diet. This long term diet (16 weeks) is widely used to induce NASH but a glucose intolerance along with insulin resistance appear earlier after 4 weeks of diet along with weight gain (Charlton et al., 2011; Dissard et al., 2013; Tsuchiya et al., 2013). As expected we observed in WT mice fed HF-HF a weight gain from one week and a glucose intolerance at 6 weeks that are mainly due to an increase in fat mass and a decrease in locomotor activity and in energy expenditure. One of the most striking effect of $H n f 4 g$ gene invalidation is a weight gain and a glucose intolerance protection against HF-HF diet. We could expect an increase in energy expenditure or in locomotor activity to explain this protection. However, energy homeostasis analysis in metabolic cages does not show differences between WT and $\mathrm{Hnf}_{4} \mathrm{~g}^{-/-}$mice fed HF-HF. We hypothesized that $H n f 4 g$ gene invalidation induces a loss of ingested calories and we showed increased calories in feces. We made the hypothesis of a lipid failing absorption revealed by the HF-HF diet challenge.

Enterocytes ensure the absorption of dietary lipids to the organism through complex processes that can be summarized into three major steps: uptake, storage and/or secretion (Williams, 2008). The increase lipid content in feces, the decrease in intra-epithelium triglyceride content and the decrease of plasma triglyceride concentration after an olive oil bolus indicate that $\mathrm{Hnf} 4 \mathrm{~g}$ gene invalidation in HF-HF diet fed mice leads to a lipid malabsorption at the three major steps 
347 uptake, storage and secretion. We expected a down-regulation of lipid transporters gene expression in $\mathrm{Hnf}_{4} \mathrm{~g}^{-/}$mice fed HF-HF. Although HF-HF diet induces an increase in gene expression of fatty acid transporters, such as the Cd36 and Fabpm in jejunum of both $\mathrm{Hnf}_{4} \mathrm{~g}^{-/-}$ and WT mice, Hnf4g gene invalidation impacts the gene expression of Fatp4 and Scarbl 351 regardless the diet.

352 We could hypothesize that gene expression of lipid transporters Cd36 and Fabpm is upregulated to compensate a lipid malabsorption in $\mathrm{Hnf}_{4} \mathrm{~g}^{-/}$mice fed HF-HF. Although there is a gene overexpression of these transporters, we cannot exclude a translational down regulation of these transporters or a membrane mislocalization, both could participate in lipid 356 malabsorption.

357 Although the role of FATP4 as a transporter for fatty acid uptake remains unclear, it has been 358 shown that intestinal FATP4 is exclusively found intracellular instead of on the plasma 359 membrane. FATP4 plays a role in fatty acid uptake through its intrinsic intracellular enzymatic activity, through a process known as "vectorial acylation", i.e., the obligatory step of acyl-CoA 361 formation for fatty acid transport across the plasma membrane, from intestinal lumen toward 362 enterocytes (Digel et al., 2011; Milger et al., 2006). Thereby, a 25\% decrease in Fatp4 363 expression could participate to lipid malabsorption in $\mathrm{Hnflg}^{-/-}$mice fed HF-HF.

364 The scavenger receptor is known for its function as a cholesterol transporter SR-B1, however 365 its role in cholesterol and lipid metabolism remains unclear in intestine. It has been shown in 366 vitro that addition of lipid micelles triggers SR-B1 lipid sensing and a signaling cascade leading 367 to ApoB translocation from the apical membrane to the secretory basolateral domains (Beaslas 368 et al., 2009; Saddar et al., 2013). Some reports show that SR-B1 plays an important role in 369 intestinal chylomicron production (Bura et al., 2013; Hayashi et al., 2011). Thus, through an 370 indirect effect, the decrease in Scarbl gene expression prevents the lipid transfer in $\mathrm{Hnf}_{4} \mathrm{~g}^{-/-}$ 371 mice fed HF-HF. 
The chylomicron production loss is amplified by the decrease in gene expression of Mttp and $A p o B$ that are necessary to the production of the lipoprotein particle.

A defect in biliary acid metabolism could also account for lipid malabsorption. When the entero-hepatic biliary acid cycle leading to micelle formation is deficient, dietary lipids are not properly embedded with micelles, precluding adequate absorption by enterocytes (Nordskog et al., 2001). A down regulation of pancreatic lipase expression, enzyme responsible of dietary lipid hydrolysis before micelle embedding, could also be questioned (Alkaade and Vareedayah, 2017).

In our previous work, we demonstrated that HNF-4 $\gamma$ plays a critical role in glucose homeostasis and that HNF-4 $4 \gamma$ loss leads to an improvement of glucose tolerance through a rise of GLP-1 incretin effect (Baraille et al., 2015). Here we show that the glucose tolerance improvement is maintained in $\mathrm{Hnflg}^{-/-}$mice despite HF-HF feeding, in such a way that $\mathrm{Hnf4g}$ gene invalidation leads to a protection against the dietary glucose intolerance. The HOMA-IR was significantly increased only in WT mice fed HF-HF diet, indicating a possible protection of Hnf4g invalidation against insulin resistance too. Accordingly, the jejunum GLP-1 content is increased in $H n f 4 g^{-/}$mice fed HF-HF. The expression of Gcg gene, encoding GLP-1 in intestine, are increased in $\mathrm{Hnf}_{4} \mathrm{~g}^{-/}$mice fed control diet and are maintained in $\mathrm{Hnf}_{4} \mathrm{~g}^{-/-}$mice fed HF-HF. The loss of HNF-4 $\gamma$ improves the GLP-1 producing cell homeostasis, leading to a protection against a diet-induced deregulated glucose homeostasis.

The effects of $H n f 4 g$ gene invalidation are of two types. The first is an invalidation effect seen regardless of diet, $\mathrm{CD}$ or HF-HF. This is the case with glucose tolerance and plasma and intraepithelial concentrations of GLP-1 as well as expression of Hnf4a. The second is an effect of invalidation revealed by the HF-HF diet. This is the case with the amount of calories and lipids found in the feces as well as plasma triglyceride concentrations, thus revealing lipid malabsorption. In addition, the expression of genes involved in the uptake, storage and secretion 
of lipids such as Fatp4, Scarb1, Plin2, Mttp, and $A p o B$ is also impacted by the invalidation of Hnf4g with the HF-HF diet. It should be noted that the expression of the Fatp4 transporter is also impacted under the CD diet.

In absence of HNF- $4 \gamma$, there is an overexpression of HNF- $4 \alpha$ regardless the diet. It is difficult to assert that the observed effects were the direct consequence of HNF- $4 \gamma$ loss or resulted indirectly from $\mathrm{HNF}-4 \alpha$ increment in $\mathrm{Hnflg}^{-/-}$mouse intestine. However, we could hypothesized that HNF-4 $\alpha$ is able to compensate the loss of HNF- $4 \gamma$ for intestinal lipid absorption under control diet but that is overtaken under HF-HF diet. HNF- $4 \alpha$ and HNF- $4 \gamma$ are encoded by two different genes but share high homology in their DNA and ligand binding domains (Drewes et al., 1996; Taraviras et al., 2000). Indeed, it has been recently shown that HNF-4 $\alpha$ and HNF-4 $\gamma$ share almost all their binding sites on chromatin (Chen et al., 2019) and regulate the expression of genes involved in fatty-acid oxydation (Chen et al., 2020). However, these two transcription factors have a different spatial distribution along the crypt-villus axis, HNF- $4 \alpha$ being expressed along the crypt to villus axis and HNF-4 $\gamma$ being restricted to the villus (Sauvaget et al., 2002). Furthermore, 9 isoforms of HNF-4 $\alpha$ raised from differential splicing and from 2 different promoters have been described (Torres-Padilla et al., 2001). These isoforms can have opposite roles in colitis and colitis associated colon cancer (Chellappa et al., 2016). These observations show that the two forms of HNF-4, HNF-4 $\alpha$ and HNF-4 $\gamma$ play some specific roles but we cannot exclude redundancy for others roles, the balance between the expression of HNF- $4 \alpha$ and HNF- $4 \gamma$ being finely regulated to maintain gut homeostasis.

In recent report, it has been shown that $H n f 4 a$ and $H n f 4 g$ are redundantly required to drive intestinal differentiation (Chen et al., 2019). Genes that exhibit a direct binding of HNF-4 $\alpha$ or $\gamma$ are involved in lipid metabolim (Chen et al., 2019). However, an indirect regulation is also possible since it HNF-4 $\alpha$ and $\gamma$ function maintain also active enhancer chromatin (Chen et al., 
2019). However, the transcriptome analysis reveals that $H n f 4 g$ invalidation alters specifically the expression of 89 genes in intestine. Thus we cannot exclude a direct binding of HNF-4g on genes involved in lipid metabolism such as Fatp4 and Scarb1, the Hnf4a expression being repressed by the antisense transcript of Hnf4a previously described (Lindeboom et al., 2018). In our previous article, we showed that proglucagon (Gcg) gene transcription was not directly activated or repressed by HNF-4a or HNF-4g but rather the expression of Foxa1, Foxa2, and Is11 was enhanced, suggesting that modifications of the transcription factor network favored the GLP-1-secreting cell lineage (Baraille et al., 2015).

In conclusion, we demonstrated that loss of HNF-4 $\gamma$ in mice prevents obesity and glucose intolerance induced by HF-HF diet. The protection against metabolic deleterious effects of HFHF diet could be due to intestinal lipid malabsorption and glucose homeostasis improvement. Interestingly in human, $H N F 4 G$ was identified as an obesity-associated locus in a meta-analysis of GWAS study (Berndt et al., 2013) and could also be associated with pediatric obesity (Selvanayagam et al., 2018).

\section{Acknowledgments}

We thank C Ayassamy (Centre d'Exploration Fonctionnelle-UMRS 1138) for mouse care, C Amorin (Centre de génotypage et de biochimie - UMRS 1138) for mouse genotyping and A Lacombe (Preclin - IHU ICAN) for metabolic cage experiments.

\section{Author contribution statement}

S.A., C.O., E.G.-I., L.L.G., N.K., H.S. and A.R. designed experiments, acquired and analyzed data. S.A., H.S., F.A., K.C., P.S., A.L. and A.R. contributed to data interpretation and to the discussion. S.A., H.S., P.S., A.L. and A.R. wrote the manuscript. P.S. and A.R. reviewed and edited manuscript. A.R. is the guarantor of this work and, as such, had full access to all data in 
446 the study and takes responsibility for the integrity of the data and the accuracy of the data 447 analysis.

448

\section{Funding}

450 This work was supported by INSERM, France, and Pierre \& Marie Curie University (UPMC), 451 Paris, France. S.A. and L.L.G. were recipient of a doctoral fellowship from Sorbonne 452 Université. E.G.I. was recipient of an internship fellowship from University of Navarra and 453 Caixa Bank (Spain).

454

455 Declaration of interest

456 No potential conflicts of interest relevant to this article were reported.

457

458 Prior presentation. Parts of these data were presented at $51^{\text {st }}$ annual meeting of the European 459 Association for the Study of Diabetes (Diabetologia, 58 S28, 2015).

460

461 


\section{References}

Adeli, K., and Lewis, G.F. (2008). Intestinal lipoprotein overproduction in insulin-resistant states. Curr Opin Lipidol 19, 221-228.

Alkaade, S., and Vareedayah, A.A. (2017). A primer on exocrine pancreatic insufficiency, fat malabsorption, and fatty acid abnormalities. Am J Manag Care 23, S203-S209.

Archer, A., Sauvaget, D., Chauffeton, V., Bouchet, P.E., Chambaz, J., Pincon-Raymond, M., Cardot, P., Ribeiro, A., and Lacasa, M. (2005). Intestinal apolipoprotein A-IV gene transcription is controlled by two hormone-responsive elements: a role for hepatic nuclear factor-4 isoforms. Mol Endocrinol 19, 2320-2334.

Bansal, S., Buring, J.E., Rifai, N., Mora, S., Sacks, F.M., and Ridker, P.M. (2007). Fasting compared with nonfasting triglycerides and risk of cardiovascular events in women. JAMA 298, 309-316.

Baraille, F., Ayari, S., Carriere, V., Osinski, C., Garbin, K., Blondeau, B., Guillemain, G., Serradas, P., Rousset, M., Lacasa, M., et al. (2015). Glucose Tolerance Is Improved in Mice Invalidated for the Nuclear Receptor HNF-4gamma: A Critical Role for Enteroendocrine Cell Lineage. Diabetes 64, 2744-2756.

Battle, M.A., Konopka, G., Parviz, F., Gaggl, A.L., Yang, C., Sladek, F.M., and Duncan, S.A. (2006). Hepatocyte nuclear factor 4alpha orchestrates expression of cell adhesion proteins during the epithelial transformation of the developing liver. Proc Natl Acad Sci U S A 103, 8419-8424.

Beaslas, O., Cueille, C., Delers, F., Chateau, D., Chambaz, J., Rousset, M., and Carriere, V. (2009). Sensing of dietary lipids by enterocytes: a new role for SR-BI/CLA-1. PLoS One $4, \mathrm{e} 4278$.

Benoit, G., Cooney, A., Giguere, V., Ingraham, H., Lazar, M., Muscat, G., Perlmann, T., Renaud, J.P., Schwabe, J., Sladek, F., et al. (2006). International Union of Pharmacology. LXVI. Orphan nuclear receptors. Pharmacol Rev 58, 798-836.

Berndt, S.I., Gustafsson, S., Magi, R., Ganna, A., Wheeler, E., Feitosa, M.F., Justice, A.E., Monda, K.L., Croteau-Chonka, D.C., Day, F.R., et al. (2013). Genome-wide meta-analysis identifies 11 new loci for anthropometric traits and provides insights into genetic architecture. Nat Genet 45, 501-512. 
493

494

495

496

497

498

499

500

501

502

503

504

505

506

507

508

509

510

511

512

513

514

515

516

517

518

519

520

521

522

523

Bookout, A.L., Jeong, Y., Downes, M., Yu, R.T., Evans, R.M., and Mangelsdorf, D.J. (2006). Anatomical profiling of nuclear receptor expression reveals a hierarchical transcriptional network. Cell 126, 789-799.

Bura, K.S., Lord, C., Marshall, S., McDaniel, A., Thomas, G., Warrier, M., Zhang, J., Davis, M.A., Sawyer, J.K., Shah, R., et al. (2013). Intestinal SR-BI does not impact cholesterol absorption or transintestinal cholesterol efflux in mice. J Lipid Res 54, 1567-1577.

Cattin, A.L., Le Beyec, J., Barreau, F., Saint-Just, S., Houllier, A., Gonzalez, F.J., Robine, S., Pincon-Raymond, M., Cardot, P., Lacasa, M., et al. (2009). Hepatocyte nuclear factor 4alpha, a key factor for homeostasis, cell architecture, and barrier function of the adult intestinal epithelium. Mol Cell Biol 29, 6294-6308.

Charlton, M., Krishnan, A., Viker, K., Sanderson, S., Cazanave, S., McConico, A., Masuoko, H., and Gores, G. (2011). Fast food diet mouse: novel small animal model of NASH with ballooning, progressive fibrosis, and high physiological fidelity to the human condition. Am J Physiol Gastrointest Liver Physiol 301, G825-834.

Chellappa, K., Deol, P., Evans, J.R., Vuong, L.M., Chen, G., Briancon, N., Bolotin, E., Lytle, C., Nair, M.G., and Sladek, F.M. (2016). Opposing roles of nuclear receptor HNF4alpha isoforms in colitis and colitis-associated colon cancer. Elife 5.

Chen, L., Toke, N.H., Luo, S., Vasoya, R.P., Fullem, R.L., Parthasarathy, A., Perekatt, A.O., and Verzi, M.P. (2019). A reinforcing HNF4-SMAD4 feed-forward module stabilizes enterocyte identity. Nat Genet 51, 777-785.

Chen, L., Vasoya, R.P., Toke, N.H., Parthasarathy, A., Luo, S., Chiles, E., Flores, J., Gao, N., Bonder, E.M., Su, X., et al. (2020). HNF4 Regulates Fatty Acid Oxidation and Is Required for Renewal of Intestinal Stem Cells in Mice. Gastroenterology 158, 985-999 e989.

Davidson, N.O., and Shelness, G.S. (2000). APOLIPOPROTEIN B: mRNA editing, lipoprotein assembly, and presecretory degradation. Annu Rev Nutr 20, 169-193.

Digel, M., Staffer, S., Ehehalt, F., Stremmel, W., Ehehalt, R., and Fullekrug, J. (2011). FATP4 contributes as an enzyme to the basal and insulin-mediated fatty acid uptake of $\mathrm{C}(2) \mathrm{C}(1)(2)$ muscle cells. Am J Physiol Endocrinol Metab 301, E785-796.

Dissard, R., Klein, J., Caubet, C., Breuil, B., Siwy, J., Hoffman, J., Sicard, L., Ducasse, L., Rascalou, S., Payre, B., et al. (2013). Long term metabolic syndrome induced by a high fat high fructose diet leads to minimal renal injury in C57BL/6 mice. PLoS One 8, e76703. 
Drewes, T., Senkel, S., Holewa, B., and Ryffel, G.U. (1996). Human hepatocyte nuclear factor 4 isoforms are encoded by distinct and differentially expressed genes. Mol Cell Biol 16, 925-931.

Duez, H., Lamarche, B., Uffelman, K.D., Valero, R., Cohn, J.S., and Lewis, G.F. (2006). Hyperinsulinemia is associated with increased production rate of intestinal apolipoprotein B-48-containing lipoproteins in humans. Arterioscler Thromb Vasc Biol 26, 1357-1363.

Duez, H., Pavlic, M., and Lewis, G.F. (2008). Mechanism of intestinal lipoprotein overproduction in insulin resistant humans. Atheroscler Suppl 9, 33-38.

Frochot, V., Alqub, M., Cattin, A.L., Carriere, V., Houllier, A., Baraille, F., Barbot, L., SaintJust, S., Ribeiro, A., Lacasa, M., et al. (2012). The transcription factor HNF-4alpha: a key factor of the intestinal uptake of fatty acids in mouse. Am J Physiol Gastrointest Liver Physiol 302, G1253-1263.

Gerdin, A.K., Surve, V.V., Jonsson, M., Bjursell, M., Bjorkman, M., Edenro, A., Schuelke, M., Saad, A., Bjurstrom, S., Lundgren, E.J., et al. (2006). Phenotypic screening of hepatocyte nuclear factor (HNF) 4-gamma receptor knockout mice. Biochem Biophys Res Commun $349,825-832$.

Gimeno, R.E., Hirsch, D.J., Punreddy, S., Sun, Y., Ortegon, A.M., Wu, H., Daniels, T., StrickerKrongrad, A., Lodish, H.F., and Stahl, A. (2003). Targeted deletion of fatty acid transport protein-4 results in early embryonic lethality. J Biol Chem 278, 49512-49516.

Haidari, M., Leung, N., Mahbub, F., Uffelman, K.D., Kohen-Avramoglu, R., Lewis, G.F., and Adeli, K. (2002). Fasting and postprandial overproduction of intestinally derived lipoproteins in an animal model of insulin resistance. Evidence that chronic fructose feeding in the hamster is accompanied by enhanced intestinal de novo lipogenesis and ApoB48-containing lipoprotein overproduction. J Biol Chem 277, 31646-31655.

Hayashi, A.A., Webb, J., Choi, J., Baker, C., Lino, M., Trigatti, B., Trajcevski, K.E., Hawke, T.J., and Adeli, K. (2011). Intestinal SR-BI is upregulated in insulin-resistant states and is associated with overproduction of intestinal apoB48-containing lipoproteins. Am J Physiol Gastrointest Liver Physiol 301, G326-337.

Hsieh, J., Hayashi, A.A., Webb, J., and Adeli, K. (2008). Postprandial dyslipidemia in insulin resistance: mechanisms and role of intestinal insulin sensitivity. Atheroscler Suppl 9, 7-13. 
554

555

556

557

558

559

560

561

562

563

564

565

566

567

568

569

570

571

572

573

574

575

576

577

Hwang-Verslues, W.W., and Sladek, F.M. (2010). HNF4alpha--role in drug metabolism and potential drug target? Curr Opin Pharmacol 10, 698-705.

Iqbal, J., and Hussain, M.M. (2009). Intestinal lipid absorption. Am J Physiol Endocrinol Metab 296, E1183-1194.

Layec, S., Beyer, L., Corcos, O., Alves, A., Dray, X., Amiot, A., Stefanescu, C., Coffin, B., Bretagnol, F., Bouhnik, Y., et al. (2013). Increased intestinal absorption by segmental reversal of the small bowel in adult patients with short-bowel syndrome: a case-control study. Am J Clin Nutr 97, 100-108.

Levy, E., Sinnett, D., Thibault, L., Nguyen, T.D., Delvin, E., and Menard, D. (1996). Insulin modulation of newly synthesized apolipoproteins B-100 and B-48 in human fetal intestine: gene expression and mRNA editing are not involved. FEBS Lett 393, 253-258.

Lewis, G.F., Uffelman, K., Naples, M., Szeto, L., Haidari, M., and Adeli, K. (2005). Intestinal lipoprotein overproduction, a newly recognized component of insulin resistance, is ameliorated by the insulin sensitizer rosiglitazone: studies in the fructose-fed Syrian golden hamster. Endocrinology 146, 247-255.

Li, X., Udager, A.M., Hu, C., Qiao, X.T., Richards, N., and Gumucio, D.L. (2009). Dynamic patterning at the pylorus: formation of an epithelial intestine-stomach boundary in late fetal life. Dev Dyn 238, 3205-3217.

Lindeboom, R.G., van Voorthuijsen, L., Oost, K.C., Rodriguez-Colman, M.J., Luna-Velez, M.V., Furlan, C., Baraille, F., Jansen, P.W., Ribeiro, A., Burgering, B.M., et al. (2018). Integrative multi-omics analysis of intestinal organoid differentiation. Mol Syst Biol 14, e8227.

Milger, K., Herrmann, T., Becker, C., Gotthardt, D., Zickwolf, J., Ehehalt, R., Watkins, P.A., Stremmel, W., and Fullekrug, J. (2006). Cellular uptake of fatty acids driven by the ERlocalized acyl-CoA synthetase FATP4. J Cell Sci 119, 4678-4688.

Montenegro-Miranda, P.S., van der Meer, J.H.M., Jones, C., Meisner, S., Vermeulen, J.L.M., Koster, J., Wildenberg, M.E., Heijmans, J., Boudreau, F., Ribeiro, A., et al. (2020). A Novel Organoid Model of Damage and Repair Identifies HNF4alpha as a Critical Regulator of Intestinal Epithelial Regeneration. Cell Mol Gastroenterol Hepatol 10, 209-223.

Nogueira, J.P., Maraninchi, M., Beliard, S., Padilla, N., Duvillard, L., Mancini, J., Nicolay, A., Xiao, C., Vialettes, B., Lewis, G.F., et al. (2012). Absence of acute inhibitory effect of 
insulin on chylomicron production in type 2 diabetes. Arterioscler Thromb Vasc Biol 32, 1039-1044.

Nordestgaard, B.G., Benn, M., Schnohr, P., and Tybjaerg-Hansen, A. (2007). Nonfasting triglycerides and risk of myocardial infarction, ischemic heart disease, and death in men and women. JAMA 298, 299-308.

Nordskog, B.K., Phan, C.T., Nutting, D.F., and Tso, P. (2001). An examination of the factors affecting intestinal lymphatic transport of dietary lipids. Adv Drug Deliv Rev 50, 21-44.

Plengvidhya, N., Antonellis, A., Wogan, L.T., Poleev, A., Borgschulze, M., Warram, J.H., Ryffel, G.U., Krolewski, A.S., and Doria, A. (1999). Hepatocyte nuclear factor-4gamma: cDNA sequence, gene organization, and mutation screening in early-onset autosomaldominant type 2 diabetes. Diabetes 48, 2099-2102.

Ribeiro, A., Archer, A., Le Beyec, J., Cattin, A.-L., Saint-Just, S., Pinçon-Raymond, M., Chambaz, J., Lacasa, M., and Cardot, P. (2007). Hepatic Nuclear Factor-4, a key transcription factor at the crossroads between architecture and function of epithelia. Recent Patents on Endocrine, Metabolic \& Immune Drug Discovery 1, 176-181

Robertson, M.D., Parkes, M., Warren, B.F., Ferguson, D.J., Jackson, K.G., Jewell, D.P., and Frayn, K.N. (2003). Mobilisation of enterocyte fat stores by oral glucose in humans. Gut $52,834-839$.

Saandi, T., Baraille, F., Derbal-Wolfrom, L., Cattin, A.L., Benahmed, F., Martin, E., Cardot, P., Duclos, B., Ribeiro, A., Freund, J.N., et al. (2013). Regulation of the tumor suppressor homeogene Cdx2 by HNF4alpha in intestinal cancer. Oncogene 32, 3782-3788.

Saddar, S., Carriere, V., Lee, W.R., Tanigaki, K., Yuhanna, I.S., Parathath, S., Morel, E., Warrier, M., Sawyer, J.K., Gerard, R.D., et al. (2013). Scavenger receptor class B type I is a plasma membrane cholesterol sensor. Circ Res 112, 140-151.

Sasaki, S., Urabe, M., Maeda, T., Suzuki, J., Irie, R., Suzuki, M., Tomaru, Y., Sakaguchi, M., Gonzalez, F.J., and Inoue, Y. (2018). Induction of Hepatic Metabolic Functions by a Novel Variant of Hepatocyte Nuclear Factor 4gamma. Mol Cell Biol 38.

Sauvaget, D., Chauffeton, V., Citadelle, D., Chatelet, F.P., Cywiner-Golenzer, C., Chambaz, J., Pincon-Raymond, M., Cardot, P., Le Beyec, J., and Ribeiro, A. (2002). Restriction of apolipoprotein A-IV gene expression to the intestine villus depends on a hormone- 
615

616

617

618

619

620

621

622

623

624

625

626

627

628

629

630

631

632

633

634

635

636

637

638

639

640

641

642

responsive element and parallels differential expression of the hepatic nuclear factor 4alpha and gamma isoforms. J Biol Chem 277, 34540-34548.

Selvanayagam, T., Walker, S., Gazzellone, M.J., Kellam, B., Cytrynbaum, C., Stavropoulos, D.J., Li, P., Birken, C.S., Hamilton, J., Weksberg, R., et al. (2018). Genome-wide copy number variation analysis identifies novel candidate loci associated with pediatric obesity. Eur J Hum Genet 26, 1588-1596.

Shikany, J.M., and White, G.L., Jr. (2000). Dietary guidelines for chronic disease prevention. South Med J 93, 1138-1151.

Stahel, P., Xiao, C., Nahmias, A., and Lewis, G.F. (2020). Role of the Gut in Diabetic Dyslipidemia. Front Endocrinol (Lausanne) 11, 116.

Stahl, A., Hirsch, D.J., Gimeno, R.E., Punreddy, S., Ge, P., Watson, N., Patel, S., Kotler, M., Raimondi, A., Tartaglia, L.A., et al. (1999). Identification of the major intestinal fatty acid transport protein. Mol Cell 4, 299-308.

Taraviras, S., Mantamadiotis, T., Dong-Si, T., Mincheva, A., Lichter, P., Drewes, T., Ryffel, G.U., Monaghan, A.P., and Schutz, G. (2000). Primary structure, chromosomal mapping, expression and transcriptional activity of murine hepatocyte nuclear factor 4gamma. Biochim Biophys Acta 1490, 21-32.

Torres-Padilla, M.E., Fougere-Deschatrette, C., and Weiss, M.C. (2001). Expression of HNF4alpha isoforms in mouse liver development is regulated by sequential promoter usage and constitutive 3' end splicing. Mech Dev 109, 183-193.

Tsuchiya, H., Ebata, Y., Sakabe, T., Hama, S., Kogure, K., and Shiota, G. (2013). High-fat, high-fructose diet induces hepatic iron overload via a hepcidin-independent mechanism prior to the onset of liver steatosis and insulin resistance in mice. Metabolism 62, 62-69.

Vine, D.F., Takechi, R., Russell, J.C., and Proctor, S.D. (2007). Impaired postprandial apolipoprotein-B48 metabolism in the obese, insulin-resistant JCR:LA-cp rat: increased atherogenicity for the metabolic syndrome. Atherosclerosis 190, 282-290.

Williams, K.J. (2008). Molecular processes that handle -- and mishandle -- dietary lipids. J Clin Invest 118, 3247-3259. 
Figure legends

646

647

648

649

650

651

652

653

654

655

656

657

658

659

660

661

662

663

664

665

666

667

Figure 1: Impact of high fat-high fructose diet on energy homeostasis in $\mathrm{Hnflg}^{-/}$and WT

mice. (A) Body weight of mice fed control diet or HF-HF diet during 6 weeks. Results were from 5 independent experiments with $12 \leq \mathrm{n} \leq 36$ for each condition. (B) Body fat mass evaluated by TD-MNR at 5 weeks of diet. (C) Food intake is the sum of pellet quantity and drinking water volume recorded for 5 consecutive days in metabolic cages and is expressed in $\mathrm{kcal} / \mathrm{day} / \mathrm{Kg}$ mouse. Control diet $=3.2 \mathrm{kcal} / \mathrm{g} ;$ High-fat diet $=5.24 \mathrm{kcal} / \mathrm{g}$; Fructose $30 \%=$ $1.2 \mathrm{kcal} / \mathrm{mL}$. (D) The locomotor activity is the sum of $\mathrm{XY}$ and $\mathrm{XZ}$ mean locomotor activity from 5 consecutive nights and days. (E) The energy expenditure, measured by indirect calorimetry, is the mean of the energy expenditure from 5 consecutive nights and days. Results (B-E) were from 2 independent experiments with $\mathrm{n}=5$ to 6 mice per group. ${ }^{* * * *} p<0.0001$; ** $p<0.01$; $* p<0.05 ;$ ns not significant.

\section{Figure 2: Impact of high fat-high fructose diet on intestinal nutrient absorption in $\mathrm{HnfH}^{-/-}$}

and WT mice. (A) Total fecal calories were determined by bomb calorimetry in daily collected feces from 3 to 5 consecutive days. Results are the mean of 4 independent measures during 2 experiments ( $\mathrm{n}=5$ or 6 animals in each condition). (B) The lipid content into feces from $H n f 4 g^{-/-}$ and WT mice were measured Results are the mean of 3 independent measures during 2 experiments ( $\mathrm{n}=5$ or 6 animals in each condition). (C) The amount of triglycerides stored in epithelial cells were quantified in isolated epithelial cells. (D) Plasma triglyceride concentrations were measured at 30, 60, 90 and 120 min after a 200 microL olive oil bolus (T0 is indicated by an arrow). $\mathrm{n}=4$ or 5 animals per condition. $* * * p<0.001 ; * * p<0.01$; ${ }^{*} p<$ 0.05; ns not significant. 
669

670

671

672

673

674

675

676

677

678

679

680

681

682

683

684

685

686

687

688

689

690

691

Figure 3: Impact of high fat-high fructose diet on jejunal expression of genes involved in lipid uptake, storage and secretion in $\mathrm{Hnf}_{\mathbf{f}} \mathrm{g}^{-/}$and WT mice. Quantitative RT-PCRs for gene expression of (A) fatty acid and cholesterol membrane transporters, (B) genes involved in storage and secretion of chylomicrons, (C) Hnf4a in jejunum of $H n f 4 g^{-/}$and WT mice fed control diet or HF-HF diet. The mRNA levels were normalized by cyclophilin mRNA level. Results were mean of 2 to 6 independent experiments with $\mathrm{n}=4$ to 12 mice per group. $* * * * p$ $<0.0001 ;{ }^{* * *} p<0.001 ;{ }^{* *} p<0.01 ;{ }^{*} p<0.05 ;$ ns not significant.

Figure 4: Impact of high fat-high fructose diet on the glucose homeostasis in $\mathrm{HnfHg}^{-/}$and WT mice. (A) Oral glucose tolerance test (OGTT, 3.6g glucose/kg) after 15h fasting. (B) Area under the curve of the OGTT. (C) Fasted blood glucose. Results (A-C) were mean of 6 independent experiments with $n=5$ to 7 mice per group. (D) Fasted blood insulin. (E) The HOMA-IR was calculated from blood glucose and insulin values in (C) and (D) as follow: [fasted blood glucose (mg/dL)] x [fasted blood insulin (mU/L)] / 405. Results (D-E) were mean of 3 independent experiments with $\mathrm{n}=3$ to 10 mice per group. ${ }^{* * *} p<0.001 ;{ }^{* *} p<0.01 ;{ }^{*} p$ $<0.05$; ns not significant.

Figure 5: Impact of high fat-high fructose diet on the intestinal GLP-1 homeostasis in $\boldsymbol{H n f}_{\mathbf{f}} \boldsymbol{g}^{-/}$and WT mice. (A) Total plasma total GLP-1 10 min after glucose bolus. Results were mean of 4 independent experiments. (B) Total GLP-1 content in jejunum. Results were mean of 2 independent experiments. (C) Quantitative RT-PCRs for Gcg gene expression. The mRNA levels were normalized by cyclophilin mRNA level. Results were mean of 4 independent experiments. ${ }^{* * *} p<0.001 ; * * p<0.01 ; * p<0.05$; ns not significant 
A

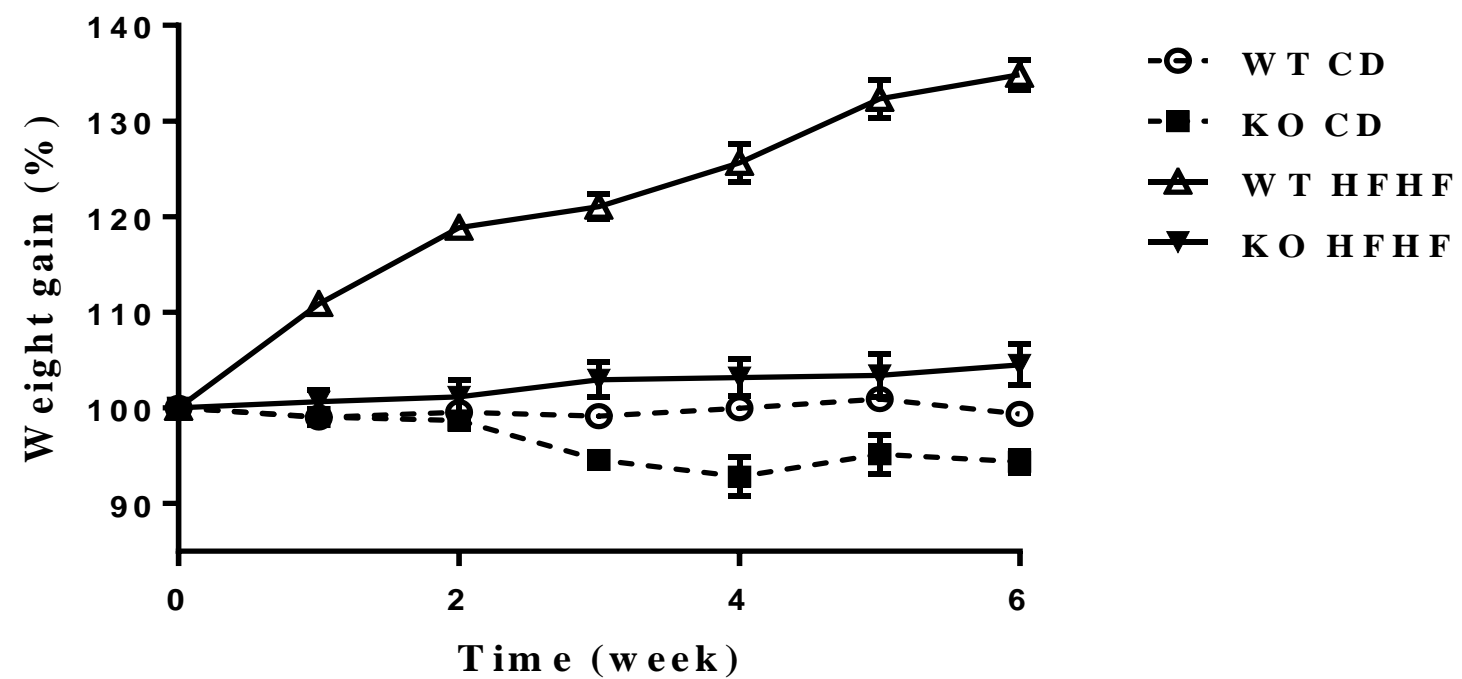

\begin{tabular}{|c|c|c|c|c|c|c|}
\hline multiple comparison test & $\mathbf{1}$ week & $\mathbf{2}$ week & $\mathbf{3}$ week & $\mathbf{4}$ week & $\mathbf{5}$ week & $\mathbf{6}$ week \\
\hline WT CD vs KO CD & $\mathrm{ns}$ & $\mathrm{ns}$ & $\mathrm{ns}$ & $\mathrm{ns}$ & $*$ & $\mathrm{~ns}$ \\
\hline WT HFHF vs KO HFHF & $\mathrm{ns}$ & $* *$ & $* *$ & $* *$ & $* * *$ & $* * * *$ \\
\hline WT CD vs WT HF-HF & $\mathrm{ns}$ & $* *$ & $* * *$ & $* * *$ & $* * *$ & $* * * *$ \\
\hline KO CD vs KO HF-HF & $\mathrm{ns}$ & $\mathrm{ns}$ & $\mathrm{ns}$ & $\mathrm{ns}$ & $\mathrm{ns}$ & $\mathrm{ns}$ \\
\hline
\end{tabular}

B

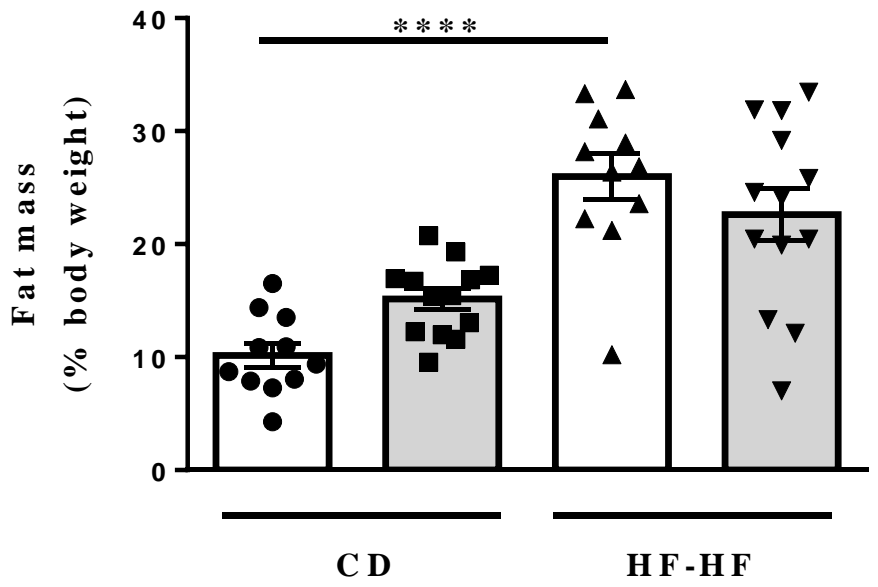

D

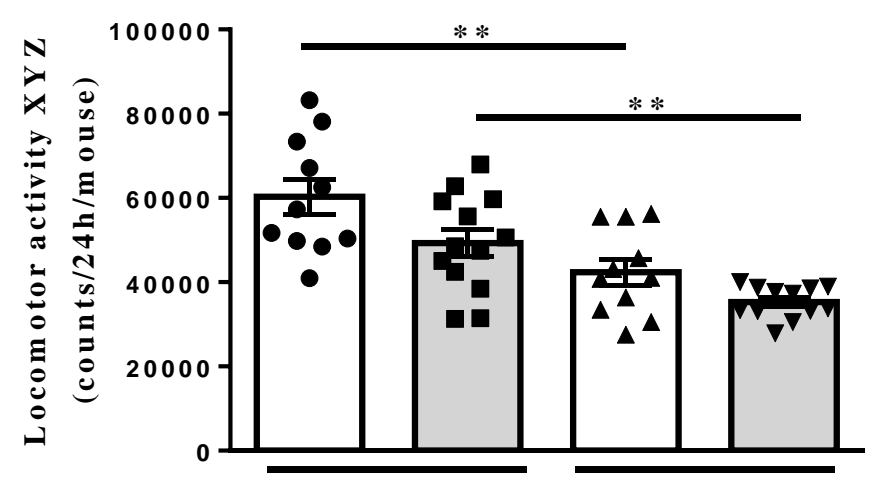

C D

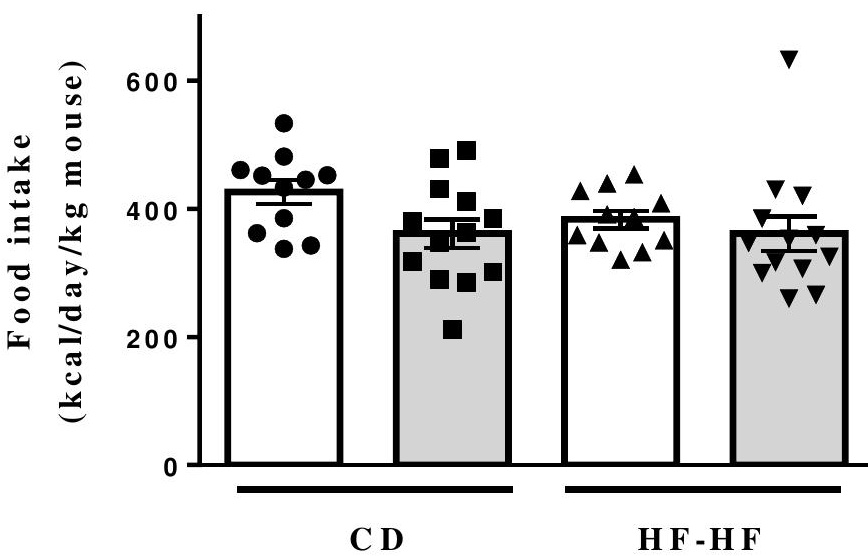

$\mathbf{E}$

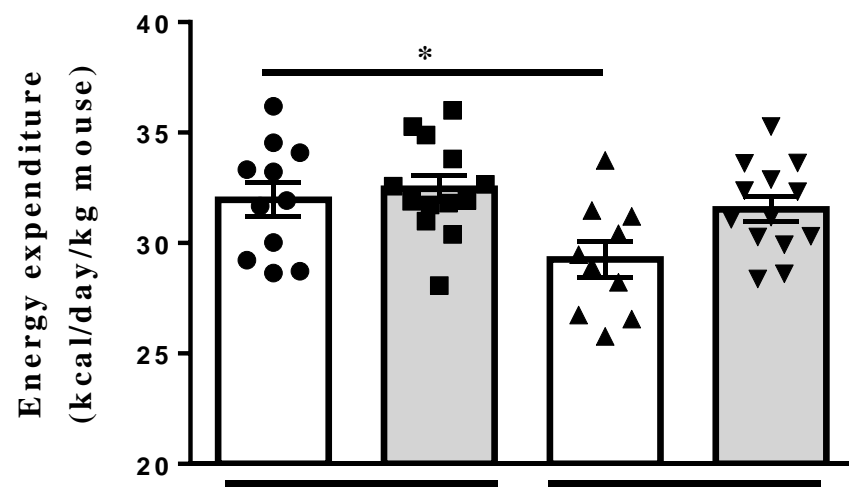

C D

H F - H F 
A

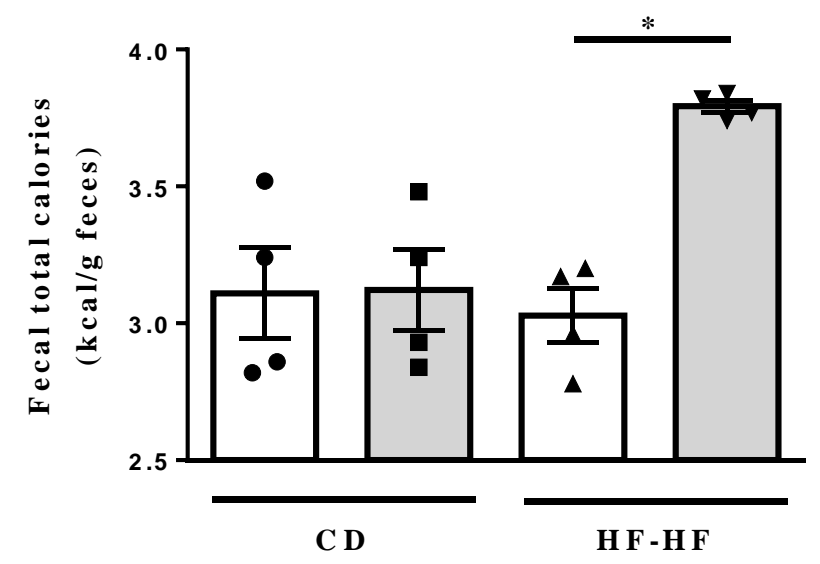

B

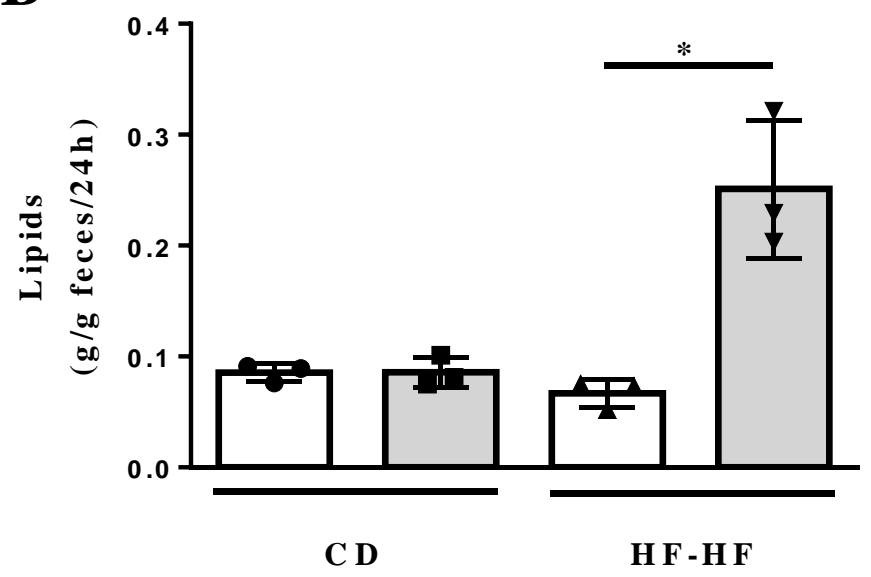

C

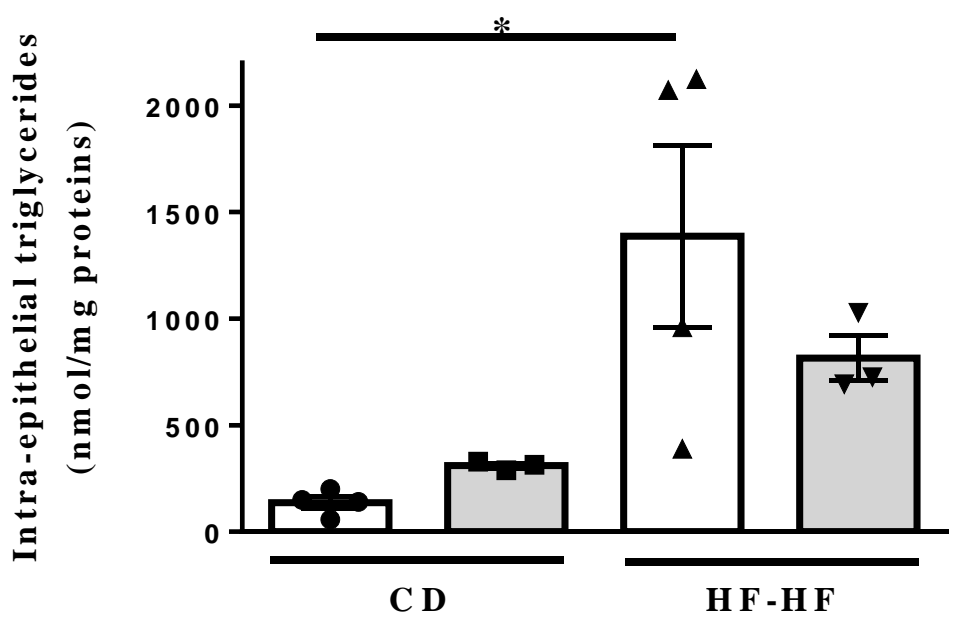

WT

$\mathrm{Hnf}_{4} \mathrm{~g}^{-/}$

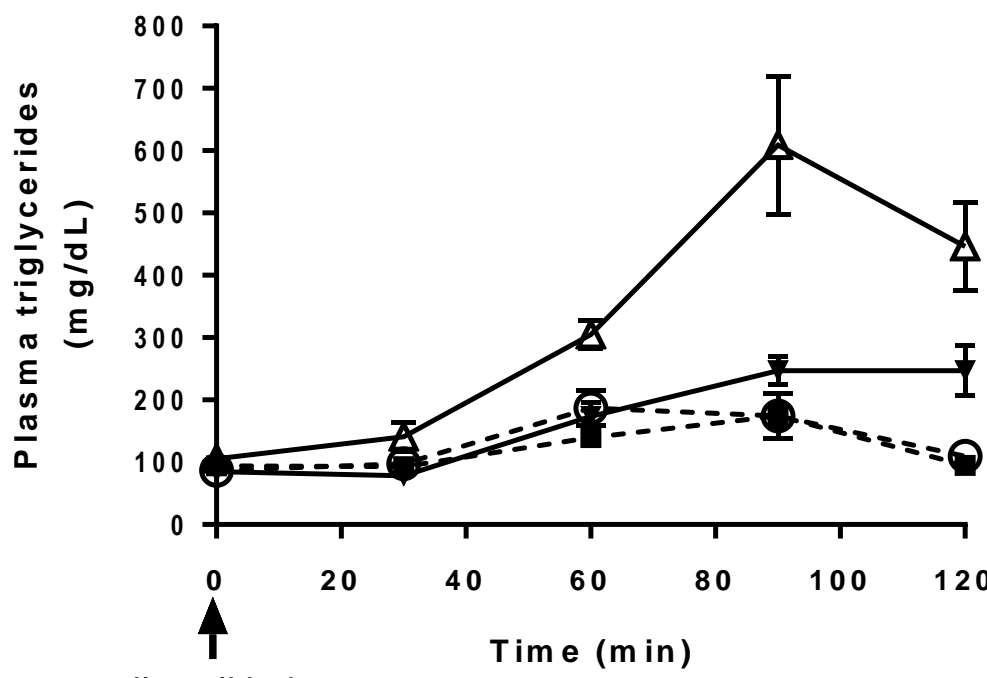

- $W T$ T D

-I. KOCD

$\triangle$ WT HF/HF

$\rightarrow \mathrm{KO} H F / H F$

olive oil bolus

\begin{tabular}{|c|c|c|c|c|}
\hline multiple comparison test & $30 \mathrm{~min}$ & $60 \mathrm{~min}$ & $90 \mathrm{~min}$ & $120 \mathrm{~min}$ \\
\hline WT CD vs KO CD & ns & ns & ns & ns \\
\hline WT HFHF vs KO HFHF & ns & ns & $* * * *$ & $* *$ \\
\hline WT CD vs WT HF-HF & ns & ns & $* * * *$ & $* * * *$ \\
\hline KO CD vs KO HF-HF & ${ }^{n} C_{0}$ & $\mathrm{ht}$ (5) 2 & oclety & Endo*crir \\
\hline
\end{tabular}


A

F A B P m

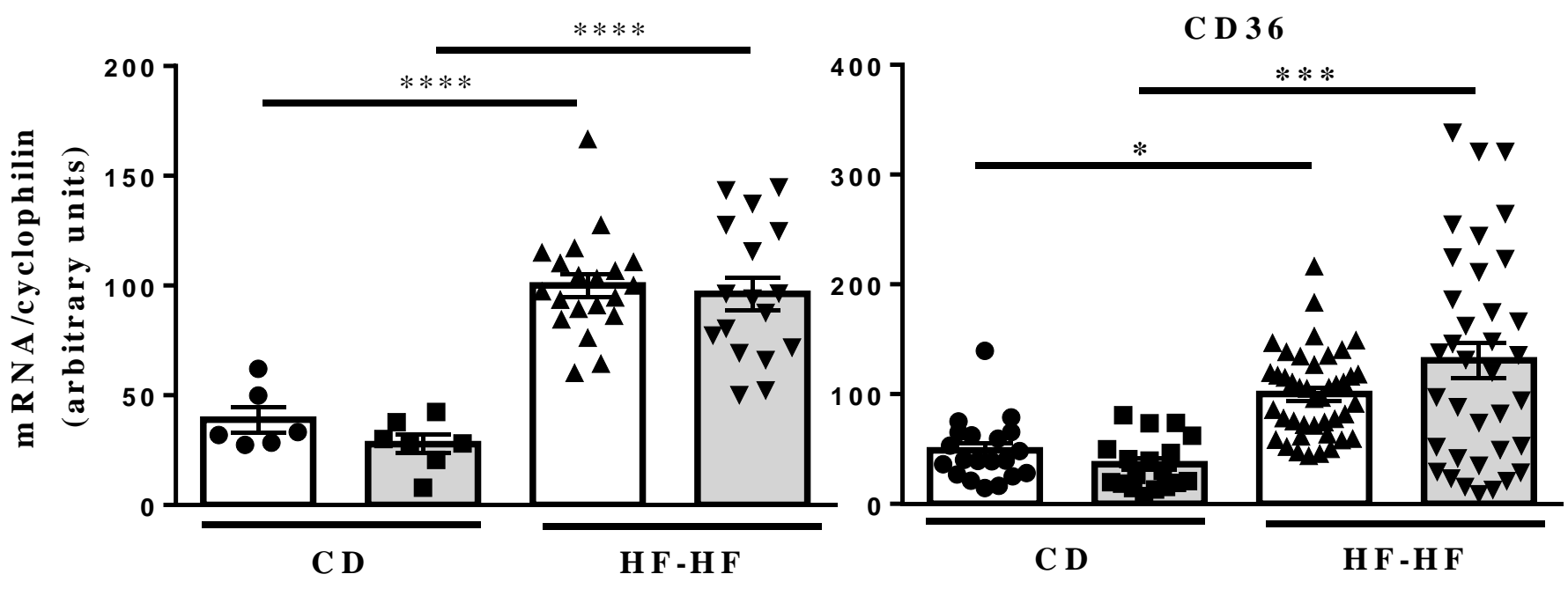

F A T P 4
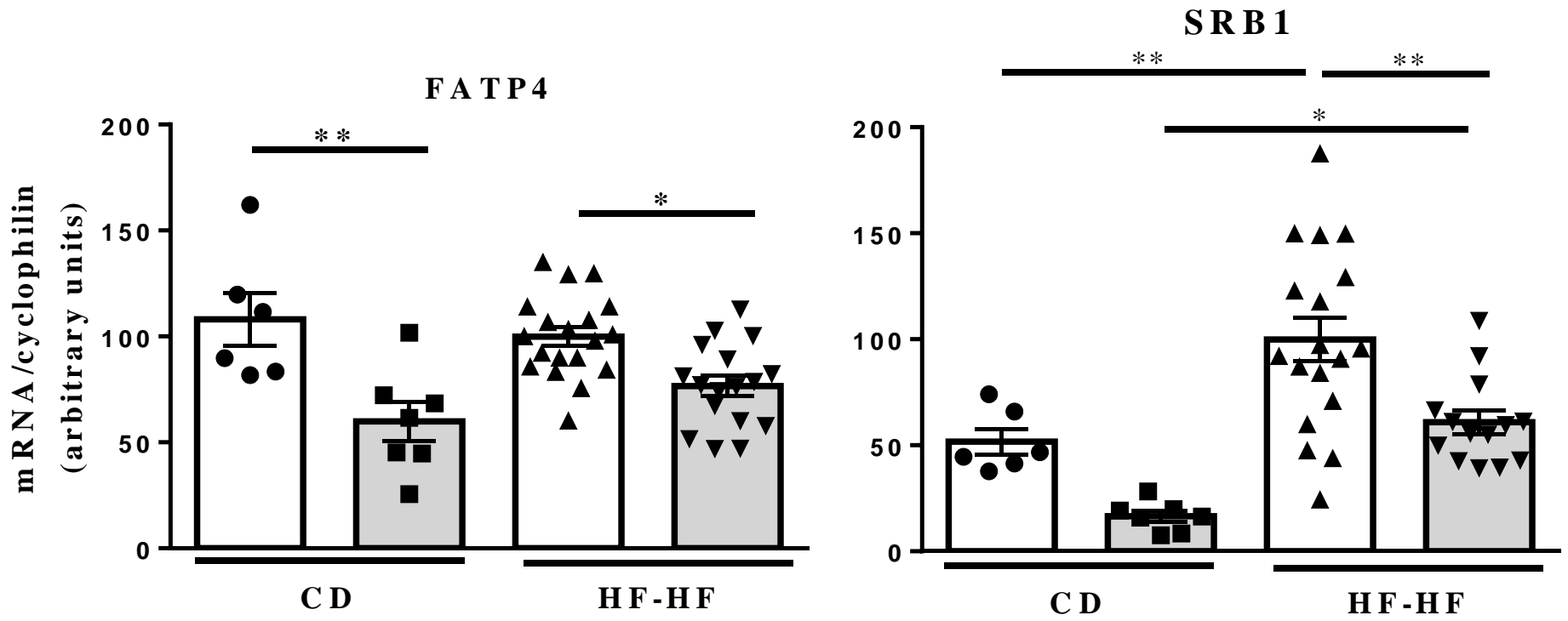
B

A D R P

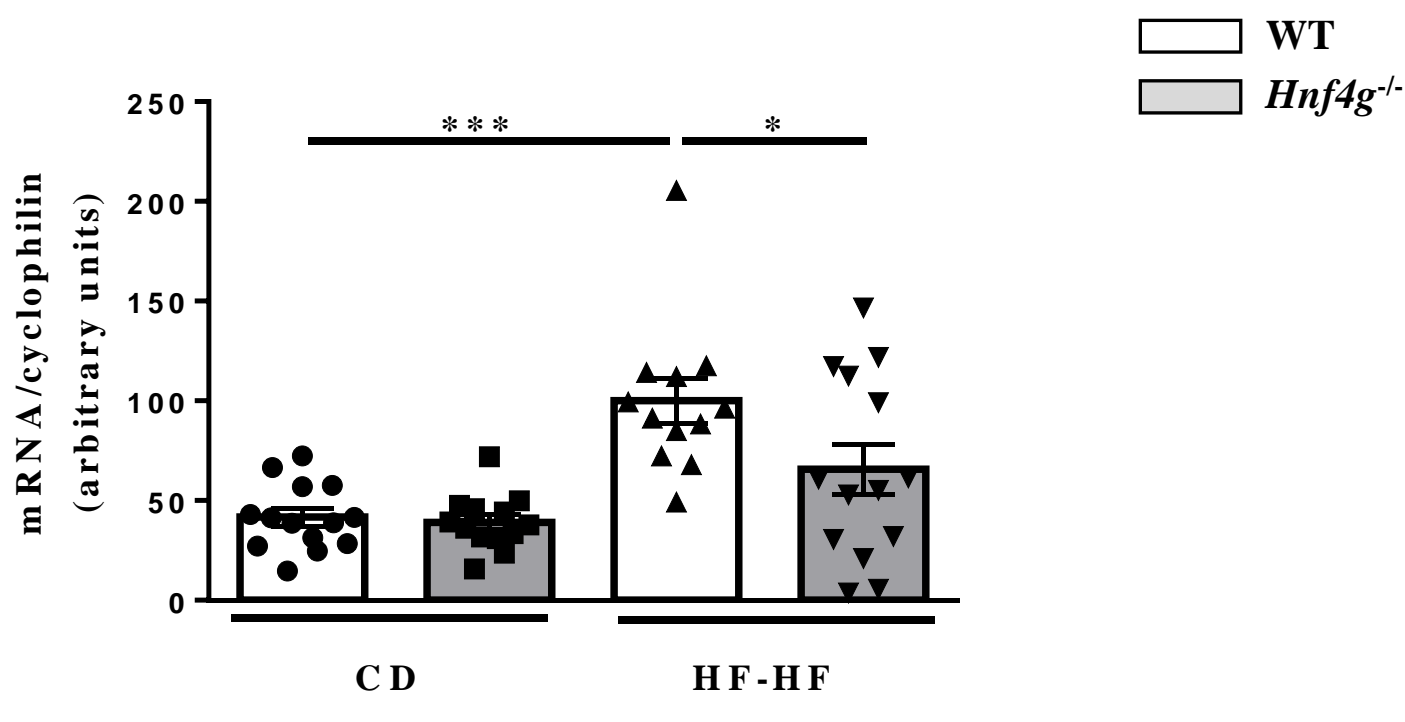

M T T P
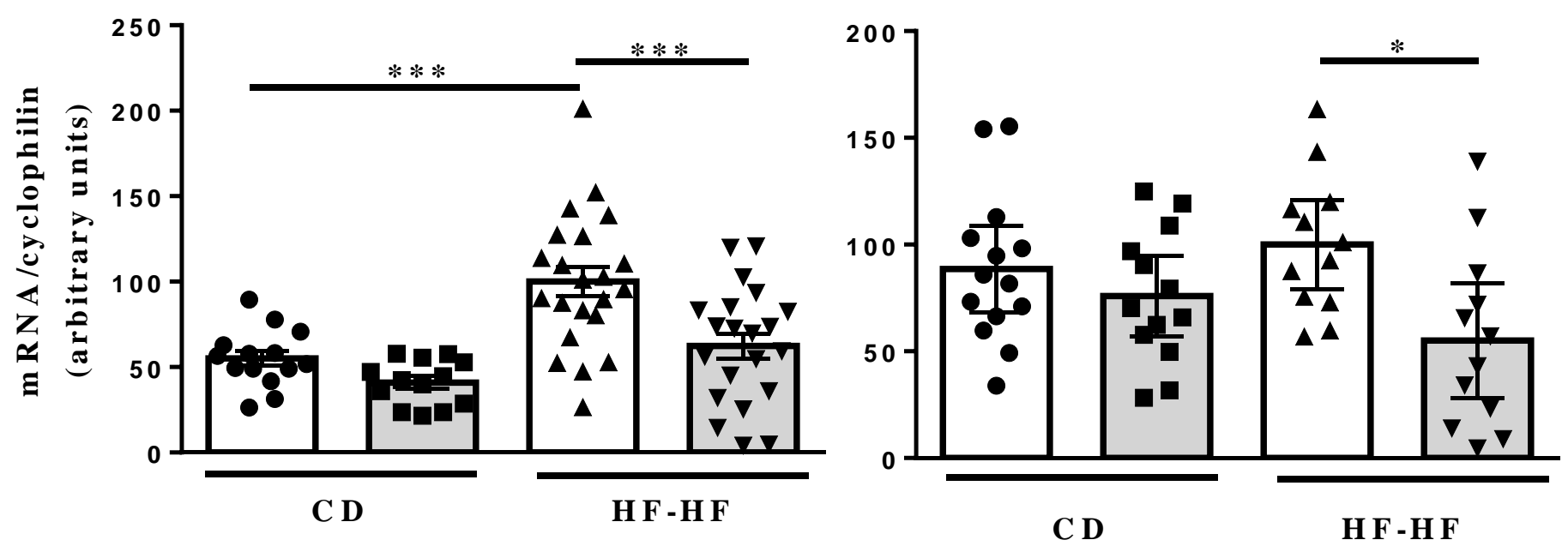

$\mathbf{C}$

H N F 4C

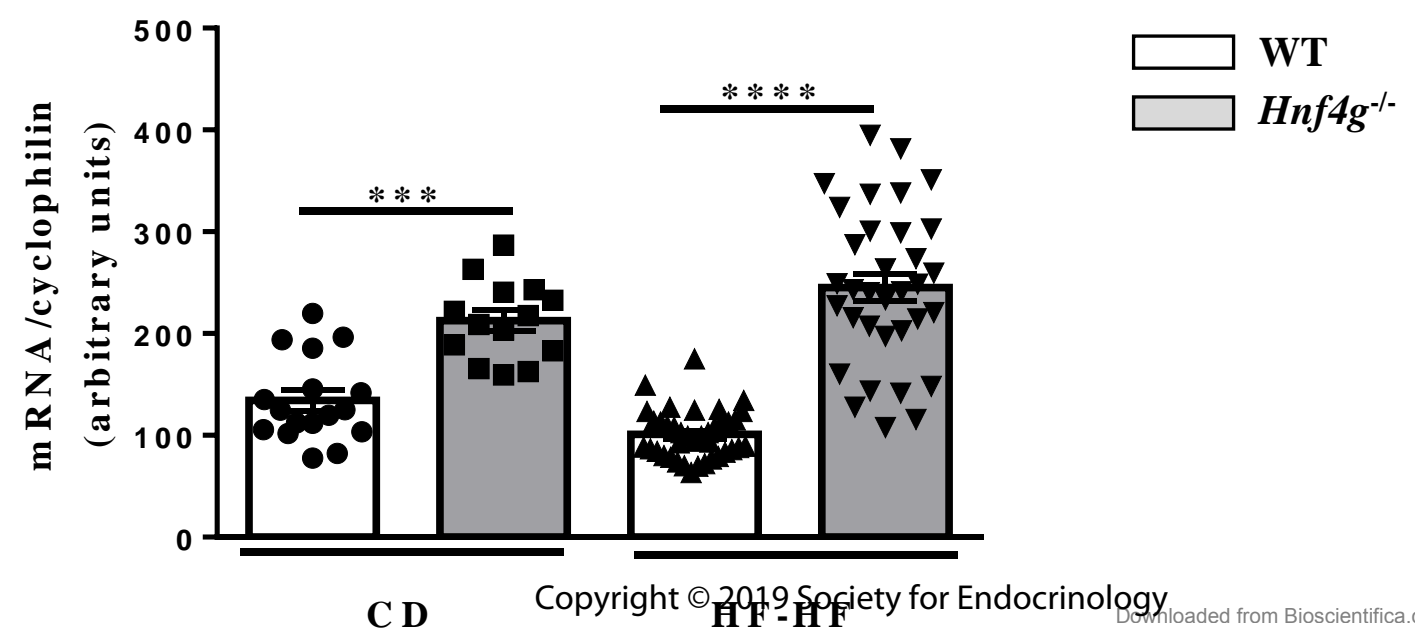

Figure 3, Ayari S \& al 
A

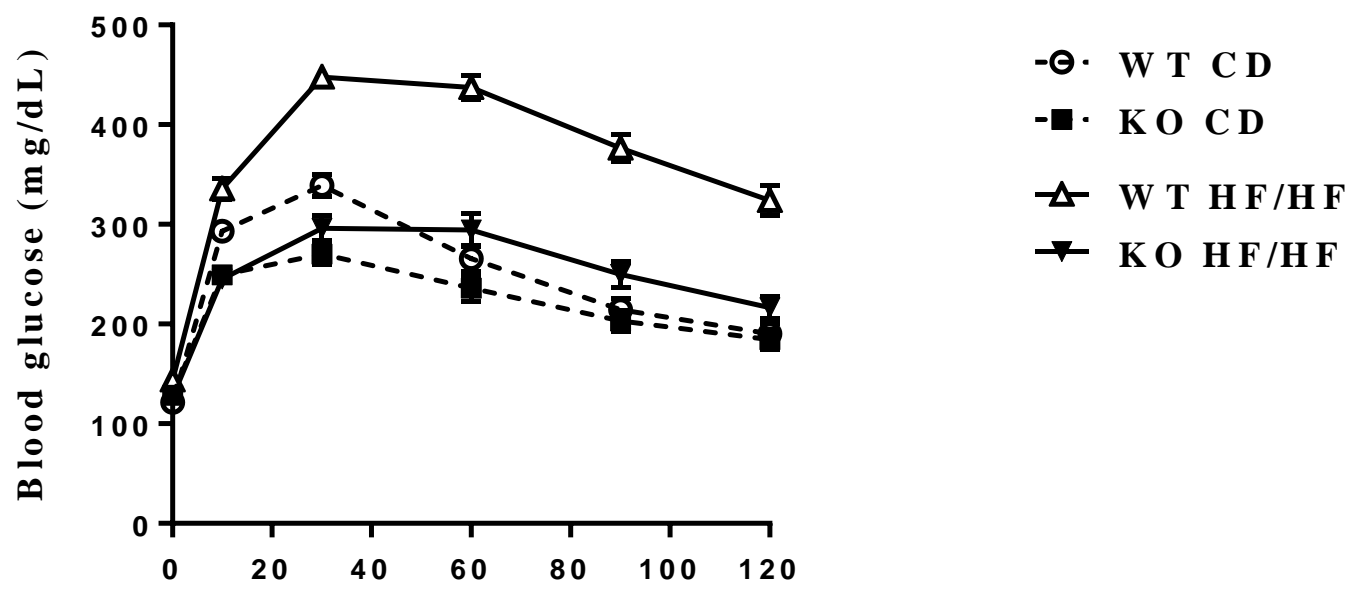

Time $(\mathrm{m}$ in)

\begin{tabular}{|c|c|c|c|c|c|}
\hline multiple comparison test & $10 \mathrm{~min}$ & $30 \mathrm{~min}$ & $60 \mathrm{~min}$ & $90 \mathrm{~min}$ & $120 \mathrm{~min}$ \\
\hline WT CD vs KO CD & $*$ & $* * * *$ & $\mathrm{~ns}$ & $\mathrm{~ns}$ & $\mathrm{~ns}$ \\
\hline WT HFHF vs KO HFHF & $* * * *$ & $* * * *$ & $* * * *$ & $* * * *$ & $* * * *$ \\
\hline WT CD vs WT HF-HF & $*$ & $* * * *$ & $* * * *$ & $* * * *$ & $* * * *$ \\
\hline KO CD vs KO HF-HF & $\mathrm{ns}$ & $\mathrm{ns}$ & $* *$ & $*$ & $\mathrm{~ns}$ \\
\hline
\end{tabular}

B

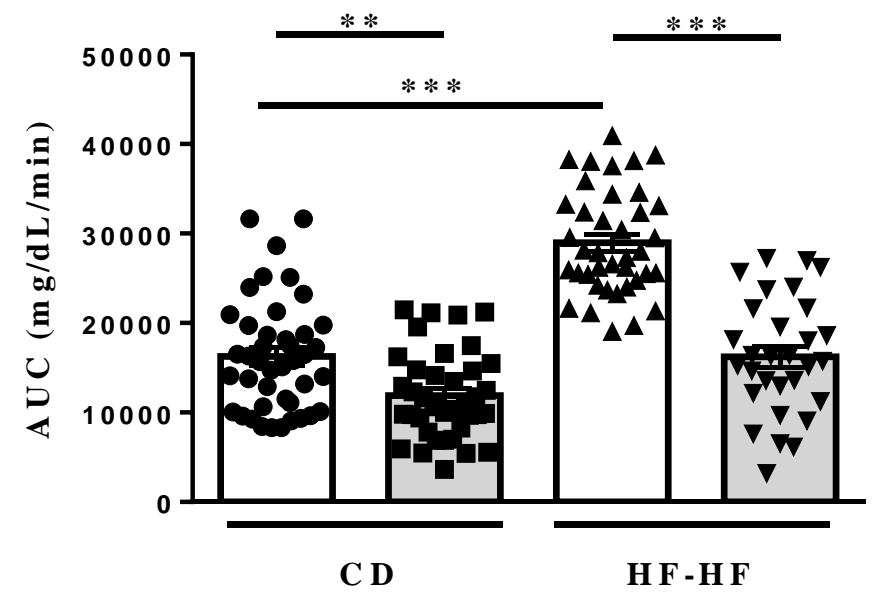

D

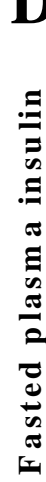

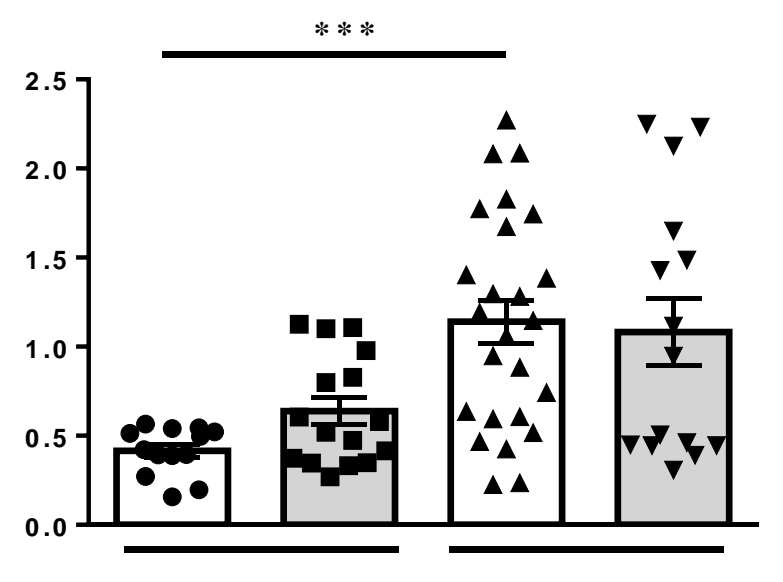

C D

Copylfogh (2019 Society for Endocrinology

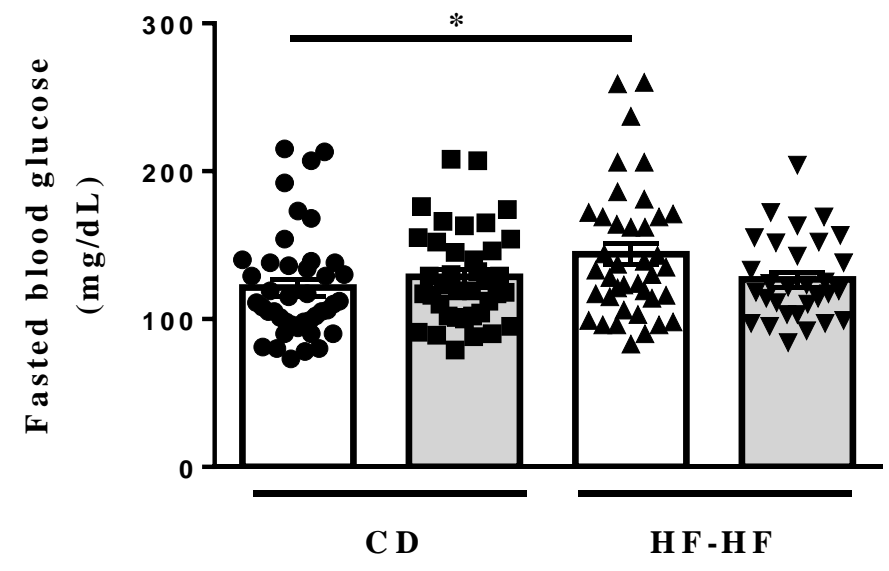

$\mathbf{E}$

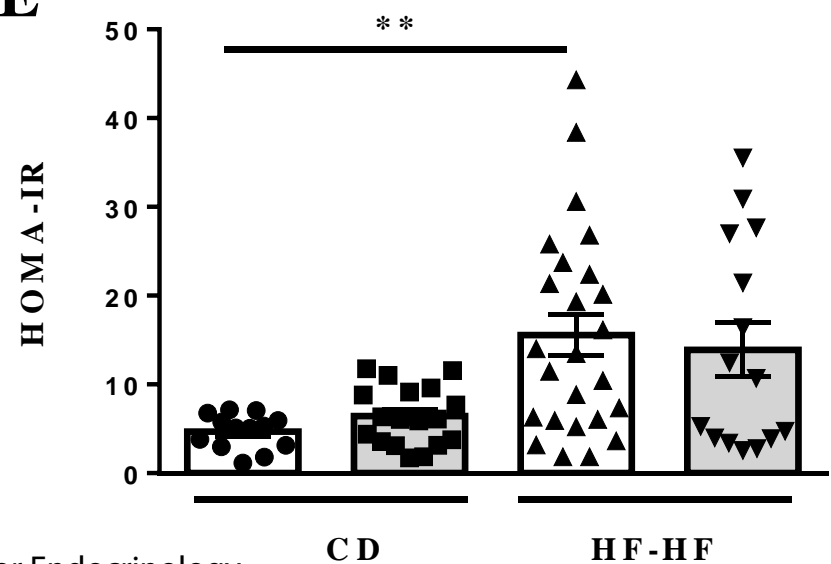

Figure 4, Ayari S \& al 
A

$$
10 \text { min after glucose bolus }
$$

$\square$ WT
$\square{\text { Hnf } 4 g^{-/-}}^{-}$

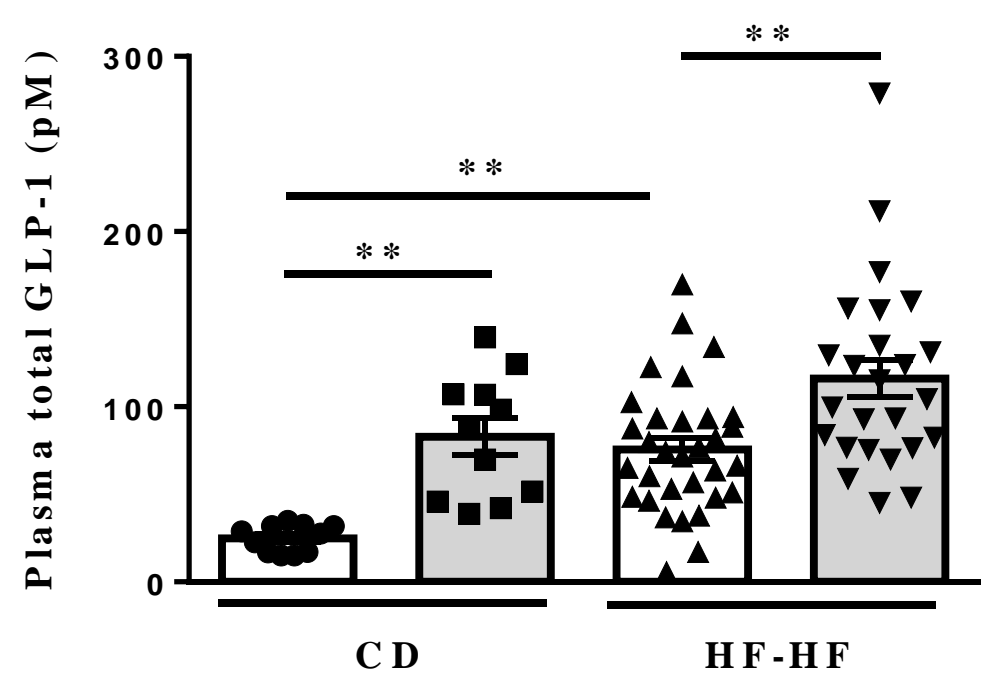

B

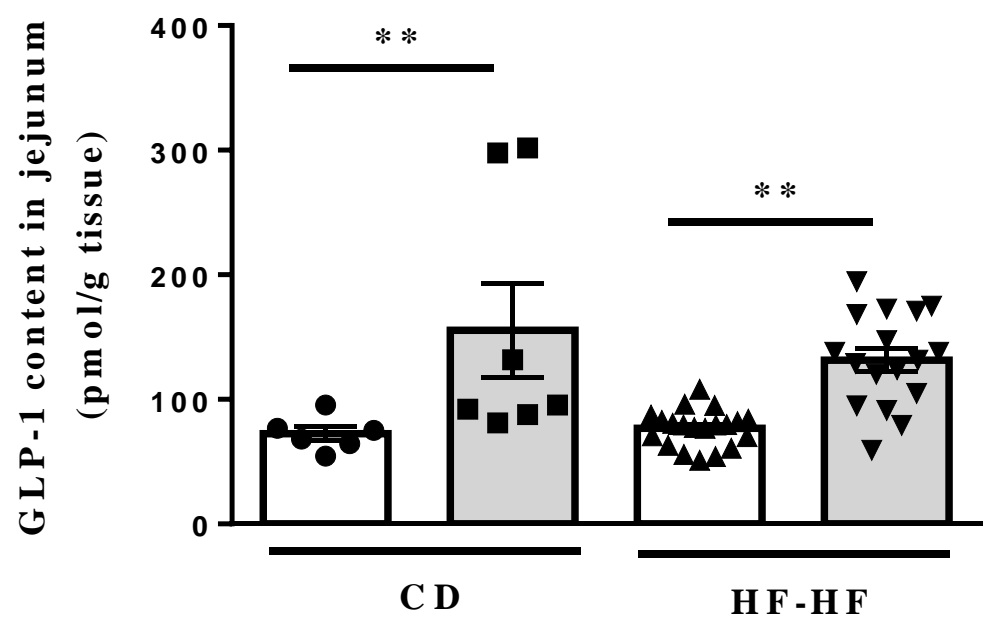

C

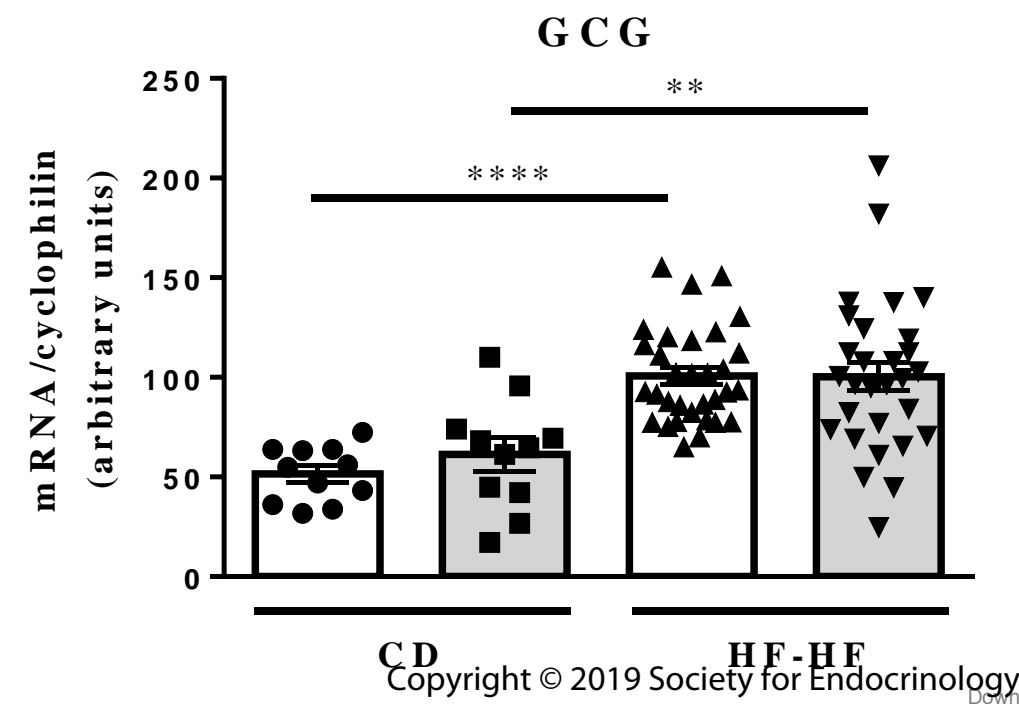
Figure 5, Ayari S \& al 


\section{Table 1}

Composition of control and high-fat diets

\begin{tabular}{|c|c|c|}
\hline & $\begin{array}{c}\text { Control diet } \\
\text { (CD) }\end{array}$ & $\begin{array}{c}\text { High-Fat diet } \\
\text { (HFD) }\end{array}$ \\
\hline \multicolumn{3}{|l|}{ Energy composition } \\
\hline Proteins (Kcal \%) & 25.2 & 20 \\
\hline Lipids (Kcal \%) & 13.5 & 60 \\
\hline Carbohydrates (Kcal \%) & 61.3 & 20 \\
\hline \multicolumn{3}{|l|}{ Energy value } \\
\hline (kcal / g) & 3200 & 5240 \\
\hline \multicolumn{3}{|l|}{ Nutrient composition } \\
\hline Proteins (\%) & 24.34 & 26.23 \\
\hline Lipids (\%) & 5.8 & 34.89 \\
\hline lard (\%) & & 31.66 \\
\hline Carbohydrates (\%) & 43.11 & 25.04 \\
\hline $\operatorname{starch}(\%)$ & 38.1 & \\
\hline maltodextrine $(\%)$ & & 16.15 \\
\hline sugars $(\%)$ & 4.55 & \\
\hline sucrose $(\%)$ & & 8.9 \\
\hline Fibers (\%) & 20.6 & 6.46 \\
\hline Minerals and vitamins & 6.15 & 7.37 \\
\hline
\end{tabular}


Table 2

Oligonucleotide sequences used for qPCR analysis

\begin{tabular}{|c|c|}
\hline Gene name & Sequence (5' to 3') \\
\hline \multirow{2}{*}{ cyclophilin } & Fwd: GCCTTAGCTACAGGAGAGAA \\
\hline & Rev: TTTCCTCCTGTGCCATCTC \\
\hline \multirow{2}{*}{ fabpm } & Fwd: ATGGCTGCTGCCTTTCAC \\
\hline & Rev: GATCTGGAGGTCCCATTTCA \\
\hline \multirow{2}{*}{ Srb1 } & Fwd: GCCCATCATCTGCCAACT \\
\hline & Rev: TCCTGGGAGCCCTTTTTACT \\
\hline \multirow{2}{*}{ Adrp } & Fwd: CTCCACTCCACTGTCCACCT \\
\hline & Rev: GCTTATCCTGAGCACCCTGA \\
\hline \multirow{2}{*}{ Gcg } & Fwd: CACGCCCTTCAAGACACAG \\
\hline & Rev: GTCCTCATGCGCTTCTGTC \\
\hline \multirow{2}{*}{ Aро B } & Fwd: GCCCATTGTGGACAAGTTGATC \\
\hline & Rev: CCAGGACTTGGAGGTCTTGGA \\
\hline \multirow{2}{*}{ Mttp } & Fwd: GGCAGTGCTTTTTCTCTGCT \\
\hline & Rev: TGAGAGGCCAGTTGTGTGAC \\
\hline \multirow{2}{*}{ CD36 } & Fwd: GCCAAGCTATTGCGACATGA \\
\hline & Rev: ATCTCAATGTCCGAGACTTTTCAAC \\
\hline \multirow{2}{*}{ Fatp4 } & Fwd: TATGGCTTCCCTGGTGTACTAT \\
\hline & Rev: TTCTTCCGGATCACCACAGTC \\
\hline \multirow{2}{*}{ Hnf4a } & Fwd: CGTCCCTCGGCACTGTCC \\
\hline & Rev: TCCTCCAGGCTCACTTGC \\
\hline
\end{tabular}

